Article

\title{
Forecasting GNSS Zenith Troposphere Delay by Improving GPT3 Model with Machine Learning in Antarctica
}

\author{
Song $\mathrm{Li}^{1}{ }^{1}$, Tianhe $\mathrm{Xu}{ }^{1}$,, Yan $\mathrm{Xu}^{1, *}$, Nan Jiang $^{1}$ and Luísa Bastos $^{2}{ }^{\mathbb{D}}$ \\ 1 Institute of Space Science, Shandong University, Weihai 264209, China; 202121039@mail.sdu.edu.cn (S.L.); \\ thxu@sdu.edu.cn (T.X.); nanjiang@sdu.edu.cn (N.J.) \\ 2 Department of Geosciences, Environment and Spatial Planning, Faculty of Sciences, University of Porto, \\ 4169-007 Porto, Portugal; lcbastos@fc.up.pt \\ * Correspondence: yxu@sdu.edu.cn; Tel.: +86-631-5621748
}

Citation: Li, S.; Xu, T.; Xu, Y.; Jiang, N.; Bastos, L. Forecasting GNSS Zenith Troposphere Delay by Improving GPT3 Model with Machine Learning in Antarctica. Atmosphere 2022, 13, 78. https:// doi.org/10.3390/atmos13010078

Academic Editors: Katarzyna Stępniak and Maxim Golubkov

Received: 25 November 2021 Accepted: 27 December 2021 Published: 3 January 2022

Publisher's Note: MDPI stays neutral with regard to jurisdictional claims in published maps and institutional affiliations.

Copyright: (C) 2022 by the authors. Licensee MDPI, Basel, Switzerland. This article is an open access article distributed under the terms and conditions of the Creative Commons Attribution (CC BY) license (https:// creativecommons.org/licenses/by/ $4.0 /)$.

\begin{abstract}
Antarctica has a significant impact on global climate change. However, to draw climate change scenarios, there is a need for meteorological data, such as water vapor content, which is scarce in Antarctica. Global navigation satellite system (GNSS) networks can play a major role in overcoming this problem as the tropospheric delay that can be derived from GNSS measurements is an important data source for monitoring the variation of water vapor content. This work intends to be a contribution for improving the estimation of the zenith tropospheric delay (ZTD) obtained with the latest global pressure-temperature (GPT3) model for Antarctica through the use of long shortterm-memory (LSTM) and radial basis function (RBF) neural networks for modifying GPT3_ZTD. The forecasting ZTD model is established based on the GNSS_ZTD observations at 71 GNSS stations from 1 January 2018 to 23 October 2021. According to the autocorrelation of the bias series between GNSS_ZTD and GPT3_ZTD, we predict the LSTM_ZTD for each GNSS station for period from October 2020 to October 2021 using the LSTM day by day. Based on the bias between LSTM_ZTD and GPT3_ZTD of the training stations, the RBF is adopted to estimate the LSTM_RBF_ZTD of the verified station, where the LSTM_ZTD represents the temporal forecasting ZTD at a single station, and the LSTM_RBF_ZTD represents the predicted ZTD obtained from space. Both the daily and yearly RMSE are calculated against the reference (GNSS_ZTD), and the improvement of predicted ZTD is compared with GPT3_ZTD. The results show that the single-station LSTM_ZTD series has a good agreement with the GNSS_ZTD, and most daily RMSE values are within $20 \mathrm{~mm}$. The yearly RMSE of the 65 stations ranges from $6.4 \mathrm{~mm}$ to $32.8 \mathrm{~mm}$, with an average of $10.9 \mathrm{~mm}$. The overall accuracy of the LSTM_RBF_ZTD is significantly better than that of the GPT3_ZTD, with the daily RMSE of LSTM_RBF_ZTD significantly less than $30 \mathrm{~mm}$, and the yearly RMSE ranging from $5.6 \mathrm{~mm}$ to $50.1 \mathrm{~mm}$ for the 65 stations. The average yearly RMSE is $15.7 \mathrm{~mm}$, which is $10.2 \mathrm{~mm}$ less than that of the GPT3_ZTD. The LSTM_RBF_ZTD of 62 stations is more accurate than GPT3_ZTD, with the maximum improvement reaching 76.3\%. The accuracy of LSTM_RBF_ZTD is slightly inferior to GPT3_ZTD at three stations located in East Antarctica with few GNSS stations. The average improvement across the 65 stations is $39.6 \%$.
\end{abstract}

Keywords: GNSS_ZTD; GPT3; long short-term-memory; radial basis function; forecasting

\section{Introduction}

Monitoring water vapor in Antarctica is of great importance for understanding global precipitation. At present, more than 120 countries and 16 organizations have built observation stations in Antarctica. Due to the limited temporal and spatial resolution of data observed by the meteorological stations, global navigation satellite system (GNSS) observations are an effective complement for retrieving water vapor with higher temporal resolution. In previous work, based on the GNSS tropospheric delay calculated using a traditional troposphere model and surface-measured meteorological observations, precipitable 
water vapor (PWV) at Scott Base and McMurdo stations in Antarctica is determined [1]. The GNSS-PWV at three permanent GNSS tracking stations (FIE0, MCM4, ROB1) in Antarctica is estimated and compared with radiosonde data and numerical weather prediction model, giving a consistent bias of $1.7 \mathrm{~mm}$ between the GNSS solution and the radiosonde and numerical weather prediction model reference values [2]. The feasibility of using GNSS tropospheric delay to retrieve PWV in Antarctica has been verified.

Since it is difficult to obtain the observed meteorological measurements in actual applications, some troposphere delay models were built by analyzing the spatiotemporal variations of troposphere delay observations, such as IGGtrop series models [3-5], GZTD series models [6,7] and the GEOFT model [8]. Currently, more and more global meteorological reanalysis products are being adopted to compute GNSS troposphere delay and retrieval GNSS-PWV, including National Centers for Environmental Prediction (NCEP) reanalysis data [9], the five European Center for Medium-Range Weather Forecasts (ECMWF) reanalysis data (ERA5) [10-12] and the second Modern-Era Retrospective Analysis for Research and Applications (MERRA-2) [13,14]. In addition, empirical troposphere models are widely used in practical applications, such as University of New Brunswick (UNB) series models [15], European Geo-Stationary Navigation Overlay System (EGNOS) models [16], and Global Pressure and Temperature (GPT) series models [17-20]. These empirical models are developed based on local standard atmosphere or global meteorological reanalysis data. The UNB series models are proposed based on the US Standard Atmosphere to provide users of the Wide Area Augmentation System (WAAS) in North America with easier access to accurate tropospheric delay. The latest UNB3m model could estimate zenith troposphere delay (ZTD) with a bias of $-0.5 \mathrm{~cm}$ and a standard deviation of $4.9 \mathrm{~cm}$ in North America after assessment [15]. Similarly, the EGNOS guidelines recommend the use of an empirical troposphere model in the positioning process, namely the EGNOS model. The root mean square error (RMSE) of the ZTD estimated by the EGNOS model is $4.0-4.7 \mathrm{~cm}$ at 5 stations in the UK [16]. The GPT series models, including the GPT, GPT2, GPT2w and GPT3 models, are constructed with meteorological reanalysis data from the ECMWF. The GPT2w model has long been considered to be the most accurate empirical troposphere model, estimating ZTD with a mean bias of less than $1 \mathrm{~mm}$ and a standard deviation of $3.6 \mathrm{~cm}$ at 341 global GNSS sites [18]. There is no need for measured meteorological parameters when applying GPT series models as the target parameters can be obtained by extrapolation or interpolation according to the time and position information. Nevertheless, some scholars confirm that the accuracy of the above GPT models is still limited in estimating meteorological elements and tropospheric delays in Antarctica [21-23]. The GPT2 model provides pressure, temperature and water vapor pressure with lower accuracy in the Arctic and Antarctic regions, leading to inaccurate tropospheric delay estimations [21]. The accuracy analysis of the GPT2w model in Antarctica shows that the accuracy of meteorological parameters decreases and gradually stabilizes as the height increases, with ZTD being calculated with centimeter-level bias [22]. In the latest research, zenith wet delay (ZWD) series estimated by the GPT3 model are always periodic curves (too smooth), contributing to large RMSE on a global scale. An augmentation model is proposed by weighting of differences between the in situ meteorological quantities and those from the GPT3 model [23].

To overcome the poor performance of the GPT model in estimating tropospheric delay in Antarctica, here we propose the use of two machine learning methods to improve the GPT3 model and build a forecasting ZTD model in Antarctica. The existing forecast troposphere delay model in Antarctica is mainly for West Antarctica; it has not been extensively studied in East Antarctica because there are fewer stations [24]. In our approach, we model and forecast ZTD for all available GNSS sites throughout Antarctica, including stations located in East Antarctica. Furthermore, unlike the above augmentation model, the model proposed in this paper modifies the difference between the high-accuracy ZTD products and ZTD from the GPT3 model (GPT3_ZTD) in time and space, respectively. Meanwhile, two neural networks algorithms, long short-term memory (LSTM) and radial basis Function (RBF), are introduced to simulate nonlinear variations of difference series 
in the proposed model. This is different from the improved GPT2w (IGPT2w) model in China, which was established by fitting periodic signals with trigonometric functions [25]. In addition, it is found that there is a certain impact on the accuracy of the GPT2w model without considering the variation of the daily period [22]. Therefore, we adopt the strategy of day-to-day modeling and forecasting to estimate the daily period of GPT3_ZTD, which has a higher reference value for extreme weather forecasting.

\section{Data and Methodology}

\subsection{Data Source}

The experimental data used in this work is from the Nevada Geodetic Laboratory (NGL), which has provided 46,000,000 station days of tropospheric products from over 18,600 stations since 1994. We obtained them from the NGL center (http:/ / geodesy.unr. edu/gps_timeseries/trop/, accessed on 15 November 2021). These tropospheric products, including total zenith delay, north gradient, east gradient, water vapor and weighted mean temperature, were generated using JPL's GipsyX 1.0 software every 5 min [26]. The accuracy of ZTD values from NGL was confirmed to be close to the official nominal accuracy of the International GNSS Service (IGS) ZTD (4 mm) [27].

We selected ZTD at 71 GNSS stations in Antarctica with an observation time span from 1 January 2018 to 23 October 2021, which was named GNSS_ZTD. The distribution of stations and the coverage of GNSS_ZTD during the observation period are shown in Figures 1 and 2. Figure 1 indicates that most stations are located in West Antarctica, especially in the Antarctic Peninsula and on Ross Island, while only a few stations are distributed along the coast of East Antarctica. The altitude of coastal stations is lower than that of stations in inland areas, most shown in Figure 1 as blue or green points with values less than $500 \mathrm{~m}$. Detailed location information for the 71 stations can be found in official documents (http:/ / geodesy.unr.edu/NGLStationPages/llh.out_sorted_by_add_ date, accessed on 25 December 2021). Figure 2 shows that the data coverage of GNSS_ZTD exceeds $70 \%$ at most stations, although that of several stations is less than $50 \%$, and the average data coverage of all stations is $83.3 \%$.

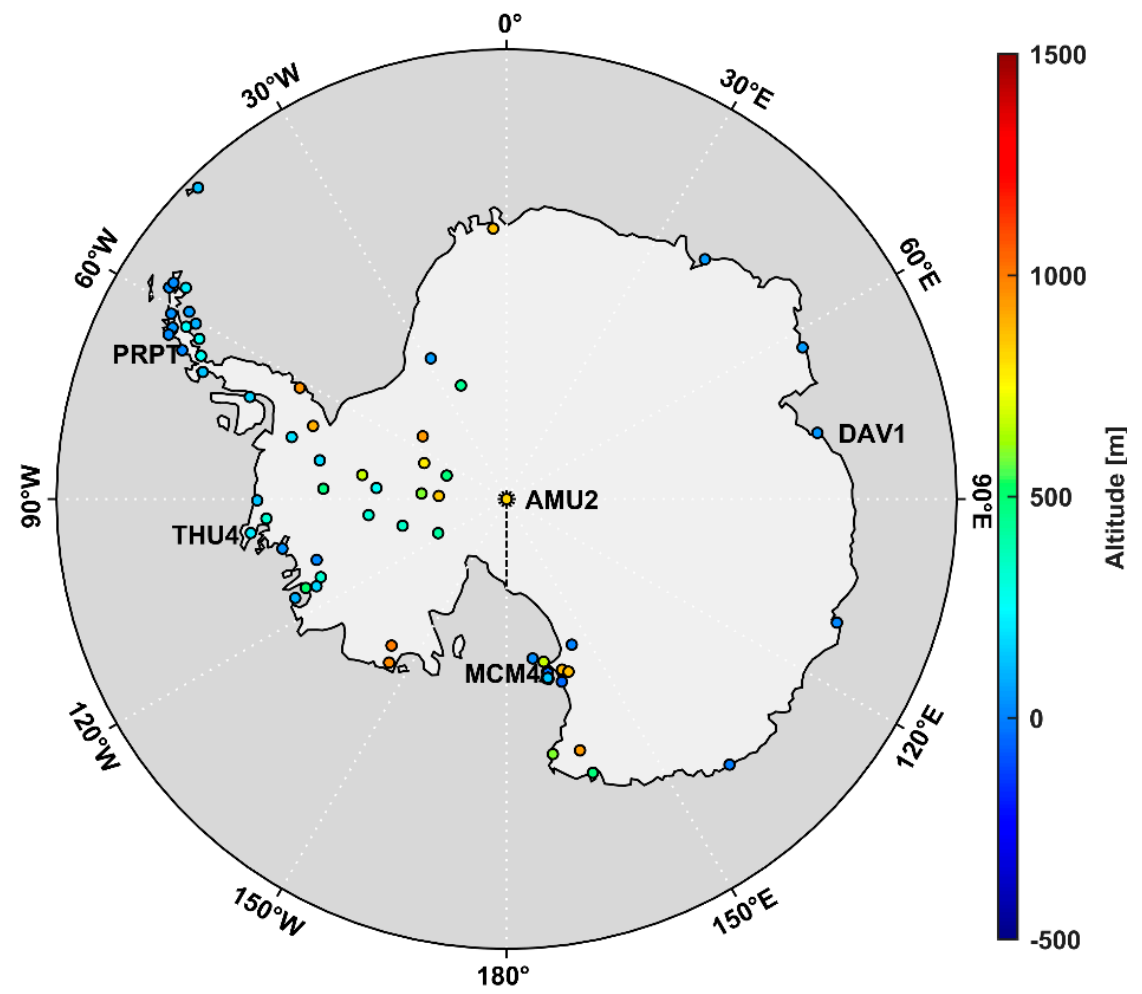

Figure 1. Distribution of experimental GNSS stations from 1 January 2018 to 23 October 2021. 


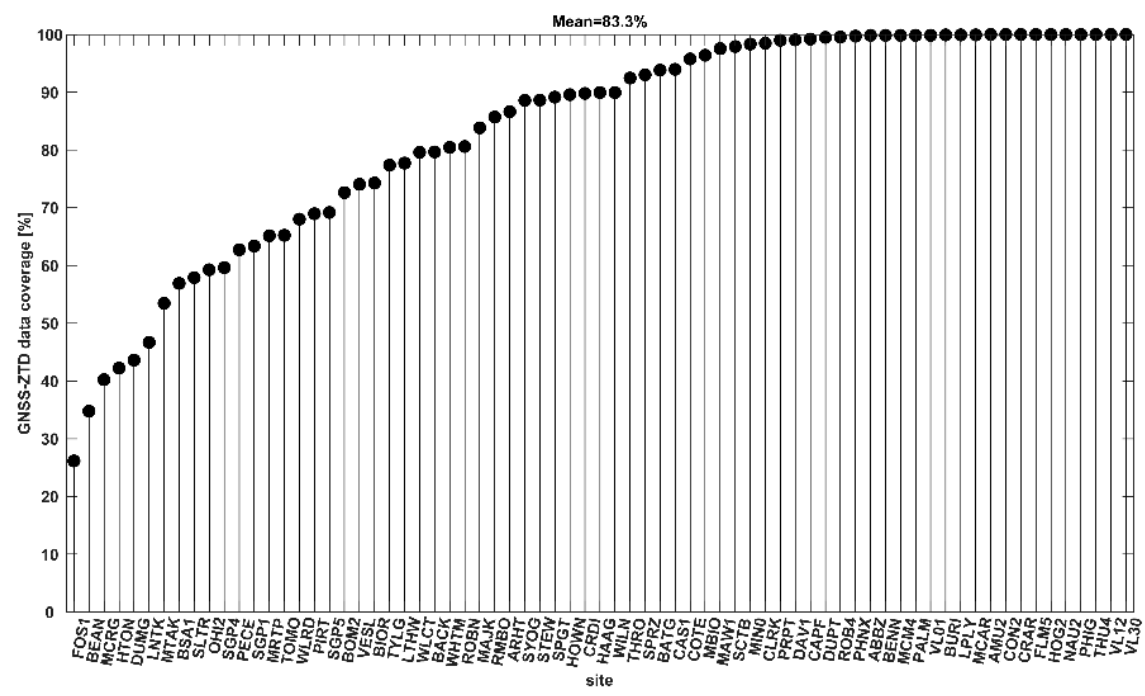

Figure 2. Data coverage of GNSS_ZTD from 1 January 2018 to 23 October 2021.

Figure 3 shows the GNSS_ZTD series in the observation period at five representative stations: the PRPT, THU4, MCM4, AMU2 and DAV1 stations (from top to bottom). These stations are located in the Antarctic Peninsula, on the coast of West Antarctica, on Ross Island, in the inland of Antarctica and on the coast of East Antarctica, respectively. The GNSS_ZTD values were largest at the PRPT, THU4, MCM4 and DAV1 stations, with mean values over $2000 \mathrm{~mm}$; the GNSS_ZTD values at the AMU2 station were relatively small, with an average value of $1544.5 \mathrm{~mm}$. Furthermore, there were obvious annual and seasonal features in the variation of GNSS_ZTD series at MCM4, AMU2 and DAV1 stations; the peaks and valleys appeared in January (warm season) and July (cold season), respectively. In addition, there were complex nonlinear high-frequency signals in GNSS_ZTD for all five stations.

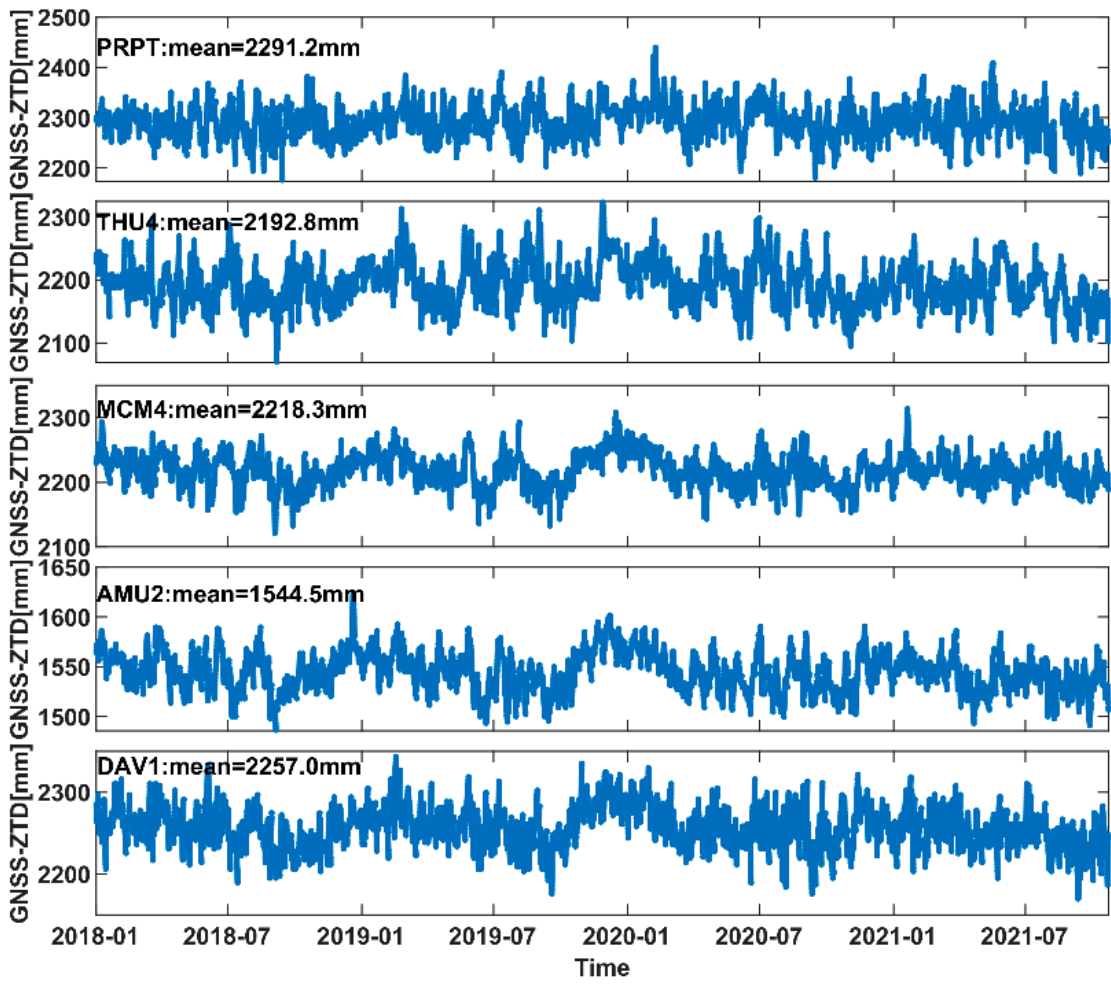

Figure 3. GNSS_ZTD series from 1 January 2018 to 23 October 2021 at PRPT, THU4, MCM4, AMU2 and DAV1 stations. 


\subsection{Method for Determining ZTD}

This section briefly explains the GPT3 model and presents the approach implemented for computing ZTD using the LSTM_RBF_ZTD model.

\subsubsection{GPT3_ZTD}

The GPT3 model provides global meteorological grid parameters (pressure $P$, temperature $T$, weighted mean temperature $T_{m}$ and specific humidity $e$ ), with spatial resolutions of $5^{\circ}$ and $1^{\circ}$, as well as the drop factor, the average value $\bar{m}$ and the variation amplitude (annual harmonic amplitudes $A_{1}, A_{2}$ and half-year harmonic amplitudes $B_{1}, B_{2}$ ) on the grid points. The target meteorological parameters $m$ were calculated at the station (longitude $\varphi$, latitude $\theta$, altitude $h$ ) for a day of the year (doy) based on the following equation [18,20]:

$$
\begin{gathered}
m(\varphi, \theta, \text { doy })=\bar{m}_{\varphi, \theta}+A_{1_{\varphi, \theta}} \cos \left(\frac{d o y}{365.25} \cdot 2 \pi\right)+A_{2_{\varphi, \theta}} \sin \left(\frac{d o y}{365.25} \cdot 2 \pi\right)+B_{1_{\varphi, \theta}} \cos \left(\frac{d o y}{365.25} \cdot 4 \pi\right) \\
+B_{2_{\varphi, \theta}} \sin \left(\frac{d o y}{365.25} \cdot 4 \pi\right)
\end{gathered}
$$

where, $\bar{m}_{\varphi, \theta}, A_{1_{\varphi, \theta}}, A_{2_{\varphi, \theta}}, B_{1_{\varphi, \theta}}, B_{2_{\varphi, \theta}}$ can be obtained by bilinear interpolating $\bar{m}, A_{1}, A_{2}$, $B_{1}, B_{2}$ based on the four nearest grid points. The Saastamoinen model and the Askne and Nordius model were adopted to compute zenith hydrostatic delay (ZHD) and ZWD with the obtained meteorological parameters [28,29].

$$
\begin{aligned}
& \mathrm{ZHD}=\frac{0.0022768 P}{1-0.00266 \cos (2 \theta)-0.00000028 h} \\
& \mathrm{ZWD}=10^{-6}\left(k_{2 p}+\frac{k_{3}}{T_{m}}\right) \cdot \frac{R_{d}}{(\alpha+1) \cdot g_{m}} \cdot e
\end{aligned}
$$

where, $g_{m}$ is the average acceleration of gravity, $\alpha$ represents the drop factor of water vapor pressure and $k_{2 p}, k_{3}, R_{d}$ are empirical constants. The calculation of GPT3_ZTD is as follows:

$$
\text { GPT3_ZTD }=\text { ZHD }+ \text { ZWD }
$$

GNSS_ZTD and GPT3_ZTD during the observation period at five representative stations (PRPT, THU4, MCM4, AMU2 and DAV1) are shown in Figure 4, as well as the difference between GPT3_ZTD and GNSS_ZTD. The GPT3_ZTD series revealed a periodic behavior, indicating that the GPT3 model was able to better estimate the annual period and seasonal variation than the high-frequency signal in the GNSS_ZTD series. The nonlinear high-frequency signal was residual and had a reflection in bias series of GPT3_ZTD with an approximate variation range of $\pm 50 \mathrm{~mm}$. Therefore, the GPT3 model performed poorly at simulating nonlinear variation of ZTD, which impacted high-precision GNSS positioning and PWV forecasting.

\subsubsection{LSTM_ZTD}

To better model the complex high-frequency variation in the GNSS_ZTD series, we analyzed the autocorrelation of the bias series between GPT3_ZTD and GNSS_ZTD (GPT3Bias). Figure 5 reveals the autocorrelation for the bias series at five representative stations, where the original GPT3-Bias, the first-order difference of GPT3-Bias and the 288-order difference of GPT3-Bias are shown from left to right, as well as the results of PRPT, THU4, MCM4, AMU2 and DAV1 station from top to bottom. It can be seen that the autocorrelation decreased slowly with increasing lag epochs in original GPT3-Bias, and decreased with a period of 288 lag epochs after the first-order difference. In addition, it tended to zero when lag epoch was greater than 288 in the 288-order difference. This demonstrates that the GPT3-Bias was strong for the autocorrelation series with a period of 288 epochs, and the current bias was strongly dependent on the bias value of the previous 288th epoch. 
Therefore, we introduced the LSTM neural network to simulate this long-term temporal dependency in the GPT3-Bias.
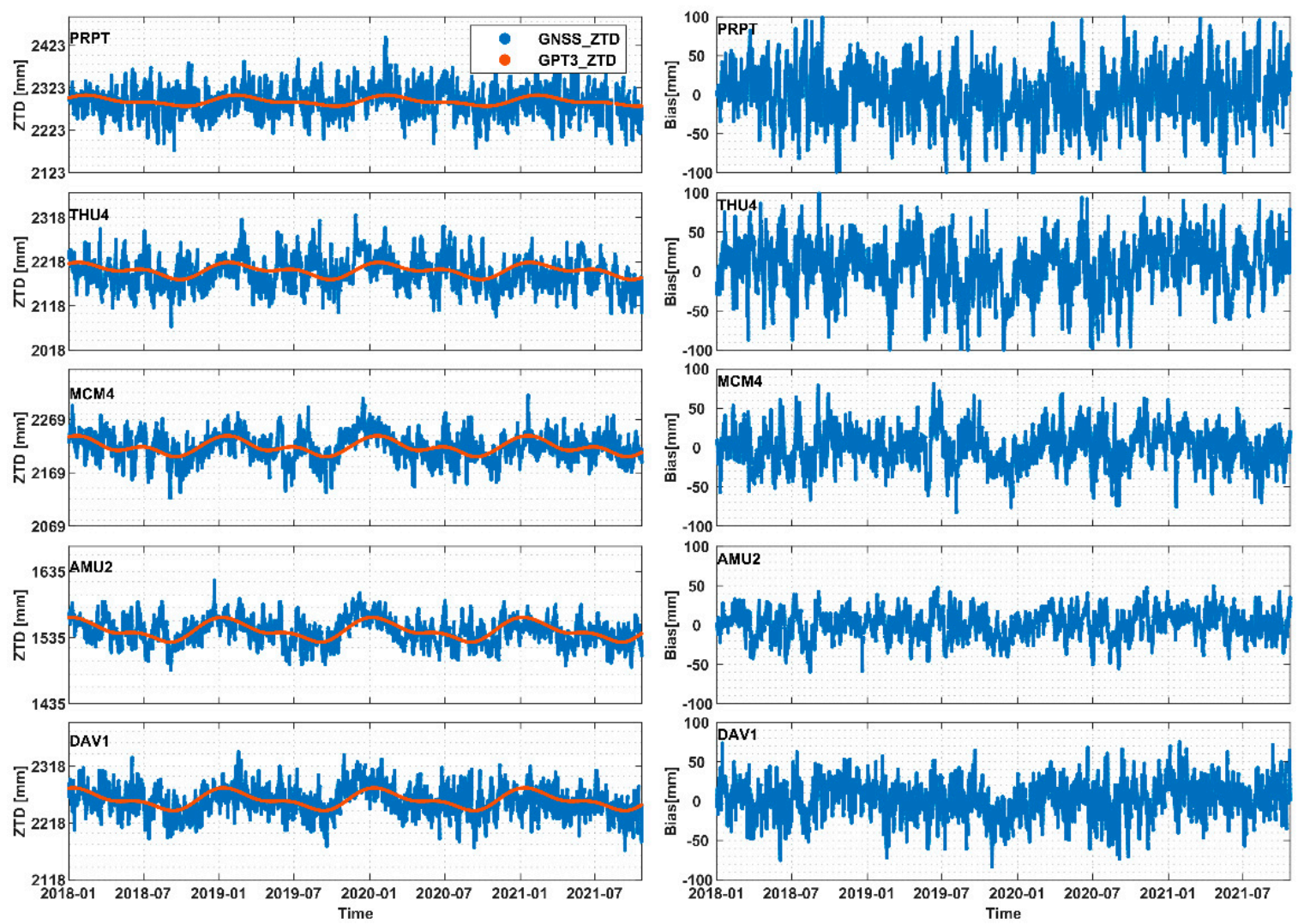

Figure 4. GNSS_ZTD, GPT3_ZTD, and bias of GPT3_ZTD and GNSS_ZTD from 1 January 2018 to 23 October 2021 at PRPT, THU4, MCM4, AMU2 and DAV1 station.

The LSTM is a special recurrent neural network (RNN) proposed by Hochreiter and Schmidhuber in 1997 [30]. This algorithm solves the problems of gradient disappearance and gradient explosion in ordinary neural networks. Unlike the feed-forward neural network, one LSTM unit contains three gates: forget gate $f_{t}$, input gate $i_{t}$ and output gate $o_{t}$. Its signal is expressed as follows:

$$
\begin{aligned}
f_{t} & =\sigma\left(\omega_{f} \cdot\left[\begin{array}{c}
x_{t} \\
h_{t-1}
\end{array}\right]+b_{f}\right) \\
i_{t} & =\sigma\left(\omega_{i} \cdot\left[\begin{array}{c}
x_{t} \\
h_{t-1}
\end{array}\right]+b_{i}\right) \\
o_{t} & =\sigma\left(\omega_{0} \cdot\left[\begin{array}{c}
x_{t} \\
h_{t-1}
\end{array}\right]+b_{0}\right)
\end{aligned}
$$

where, $h_{t-1}$ represents the state of the hidden layer at the last moment and $x_{t}$ is the input parameter at the current moment. $\omega$ and $b$ denote the weight matrix and bias parameter, respectively. The activation function is described as $\sigma$. The forget gate $f_{t}$ selectively removes the previous moment unit state $c_{t-1}$, and the input gate $i_{t}$ retains the input $X_{t}$ at the current moment. These two gates determine the current unit state $c_{t}$, which keeps previous important information and eliminates the current irrelevant content, as shown in the following:

$$
X_{t}=\tanh \left(\omega \cdot\left[\begin{array}{c}
x_{t} \\
h_{t-1}
\end{array}\right]+b\right)
$$




$$
c_{t}=f_{t} \cdot c_{t-1}+i_{t} \cdot X_{t}
$$

The output gate $o_{t}$ controls whether $c_{t}$ is outputted to the current hidden layer state $h_{t}$. The current output parameter $y_{t}$ of the LSTM network is a mapping of $h_{t}$ and is shown as:

$$
\begin{gathered}
h_{t}=o_{t} \cdot \tanh \left(c_{t}\right) \\
y_{t}=\sigma\left(\omega \cdot h_{t}\right)
\end{gathered}
$$
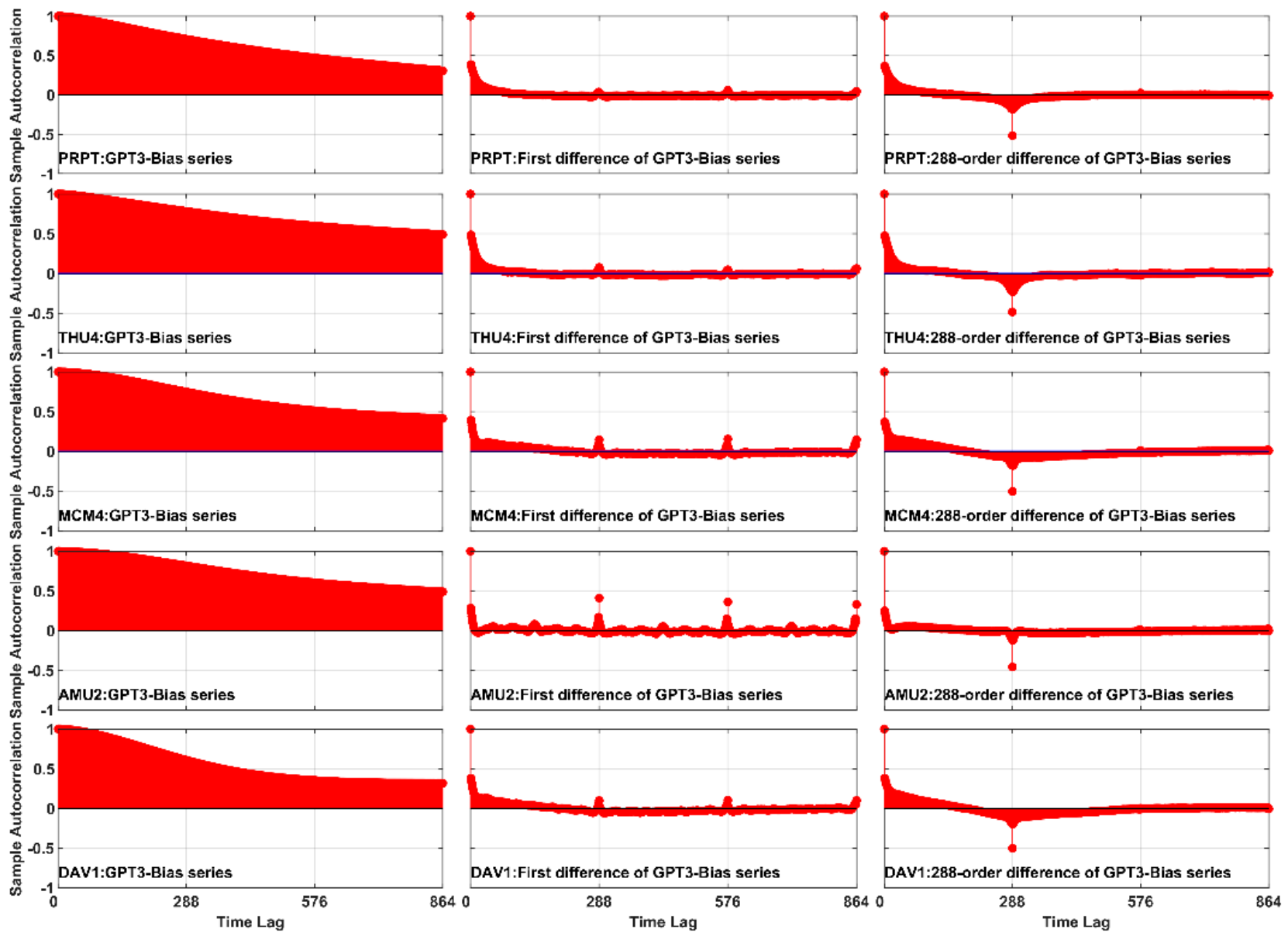

Figure 5. Autocorrelation function of bias series between GPT3_ZTD and GNSS_ZTD at PRPT, THU4, MCM4, AMU2 and DAV1 station.

As the temporal resolution of GNSS_ZTD is $5 \mathrm{~min}$, a total of 288 bias values are recorded in one day. According to the autocorrelation lag period of GPT3-Bias, the LSTM model was determined as shown in Figure 6. The input layer was composed of the bias of two days before time $t_{k}\left(D_{\mathrm{GNSS} \_Z T D} t_{k-575}, D_{\mathrm{GNSS} \_Z T D} t_{k-574}, D_{\mathrm{GNSS} \_Z T D} t_{k-573}, \ldots . . D_{\mathrm{GNSS} \_Z T D} t_{k}\right)$, the bias of

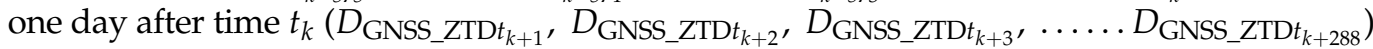
were considered the output parameters. We selected four hidden layers for the LSTM model, with the nodes of 100,100, 75 and 75, respectively. $D_{\mathrm{GNSS} Z Z T D}{ }_{i}$, similar to the GPT3-Bias, is the bias between GPT3_ZTD and GNSS_ZTD at time $t_{i}$ :

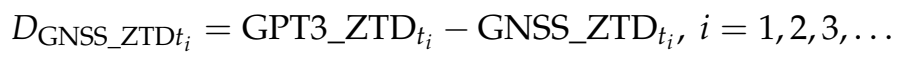




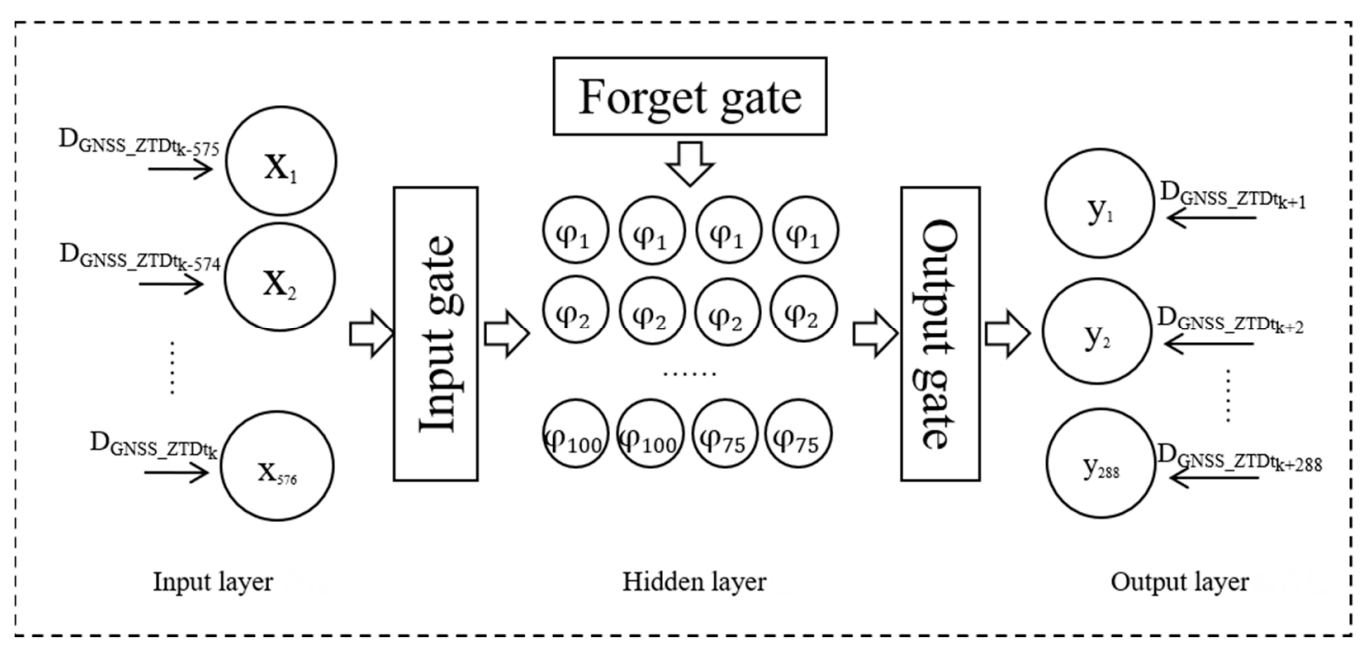

Figure 6. Structure of LSTM model.

Lastly, LSTM_ZTD is the difference of GPT3_ZTD and the estimated $D_{\text {GNSS_ZTD }}$ from the LSTM model, as shown in the following equation:

$$
\text { LSTM_ZTD }=\text { GPT3_ZTD }-D_{\text {GNSS_ZTD }}
$$

\subsubsection{LSTM_RBF_ZTD}

Based on the bias of GPT3_ZTD and LSTM_ZTD at multiple stations, the relationship between the spatial position and the bias was modeled by the RBF neural network. The single-point forecast model was extended to the regional forecast model.

The RBF neural network is a feed-forward neural network with a single hidden layer [31]. Its learning process is a local approximation that is different from the global approximation of the BP neural network, and convergence speed is faster in modeling because only critical neurons respond to an input vector. Simultaneously, the RBF neural network effectively makes up for the disadvantage that RBF function is not applicable to large samples in support vector machine (SVM). For the RBF neural network, the radial basis function is the activation function mapping the nonlinear input variables from the low-dimensional space to the high-dimensional hidden layer, and the output parameters are a linear combination of hidden layer factors. As shown in the following equations, the radial basis function is a function of the distance between the input vector $X$ and the radial basis center $c_{j}$, being the radial range controlled by the function width $\sigma$. The weight $\omega_{i j}$ connects the output $y_{i}$ and hidden-layer elements $\varphi_{j}$.

$$
\begin{gathered}
\varphi_{j}\left(\left\|X-C_{j}\right\|\right)=\exp \left(-\left\|X-C_{j}\right\|^{2} / \sigma^{2}\right) \\
y_{i}=\sum_{j=1}^{n} \varphi_{j} \times \omega_{i j}
\end{gathered}
$$

The RBF model was established day by day, as shown in Figure 7. Its input ingredients were the longitude, latitude and elevation, as well as the one-day GPT3_ZTD. The output layer was formed with the deviation between GPT3_ZTD and LSTM_ZTD, named $D_{\text {LSTM_ZTD. }}$ The hidden layer contained 16 neurons.

$$
D_{\text {LSTM_ZTD }_{i}}=\text { GPT3_ZTD } t_{i}-\text { LSTM_ZTD }_{t_{i}}, i=1,2,3, \ldots
$$




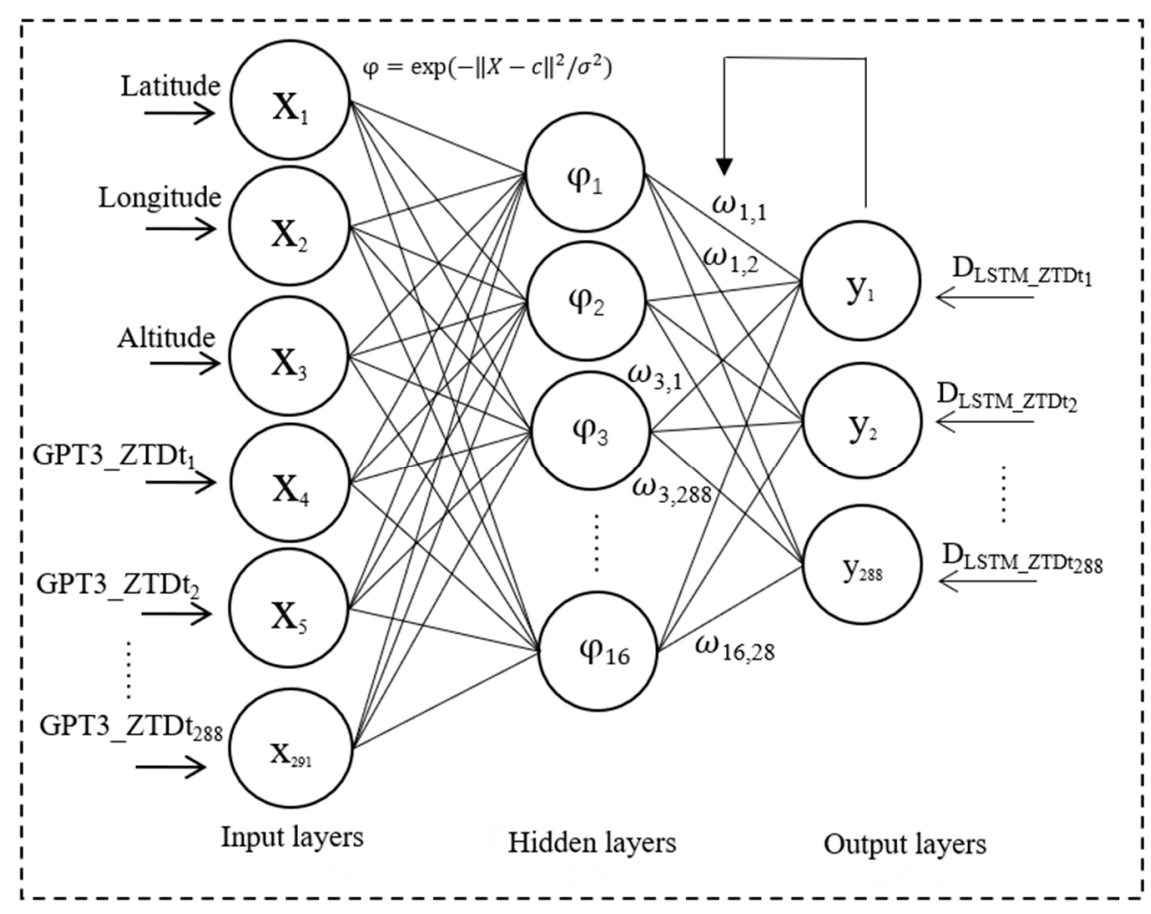

Figure 7. Structure of RBF model.

Similar to LSTM_ZTD, LSTM_RBF_ZTD is the difference between GPT3_ZTD and the estimated $D_{\text {LSTM_ZTD }}$ from the RBF model and is expressed as:

$$
\text { LSTM_RBF_ZTD }=\text { GPT3_ZTD }-D_{\text {LSTM_ZTD }}
$$

Figure 8 displays the flow diagram of the experiment conducted in this work. Firstly, the observation period was divided into the historical period and forecast period, and training stations and test stations were distinguished in the research area. Then, $D_{\mathrm{GNSS} \_ \text {ZTD }}$ series in the historical period was adopted to train the LSTM model, and the LSTM_ZTD for the forecast period was estimated by the LSTM model at the training stations. The RBF model was then established by using DLSTM_ZTD in the forecast period and coordinates of training stations. Finally, the GPT3_ZTD of the test station was improved by the RBF model to obtain the LSTM_RBF_ZTD at the test station for the forecast period.

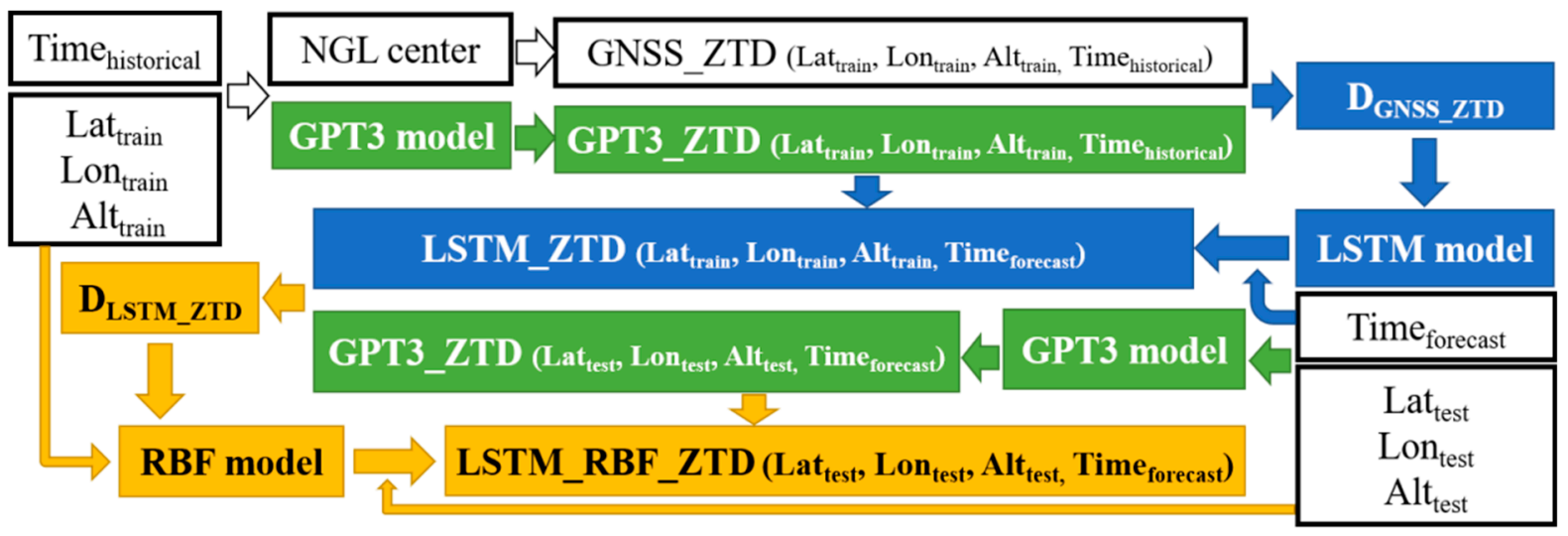

Figure 8. Flow diagram of the experiment.

\subsection{Verification}

The verification loop was performed on each of the 71 GNSS stations to comprehensively study the feasibility and applicability of the proposed model. Each day, a different 
available station in Antarctica was regarded as the test station, while the remaining were training stations participating in the modeling. The historical period was from 1 January 2018 to 23 October 2020, while the one-year period from 24 October 2020 to 23 October 2021 was considered the forecast period.

Historical data and forecast data were used to form training samples and test samples of the LSTM model, respectively. Restricted by the availability of GNSS_ZTD data, the number of samples was different when modeling at different stations. Figure 9 shows the sample number of the LSTM model at all stations. The number of training samples and test samples were more than 600 days and 200 days, respectively, at most stations, and only a small number of stations had fewer samples. The maximum was 1026 days and 365 days at stations with the GNSS_ZTD coverage of $100 \%$, the mean value of 71 stations were 877 days and 281 days, respectively. In addition, we performed training stations statistics for the RBF model in the day-to-day forecast period, as displayed in Figure 10. One test station was estimated by the RBF model each time, which was established using more than 40 training stations on most forecast days. The mean number of training stations was 54 for the one-year forecast period.

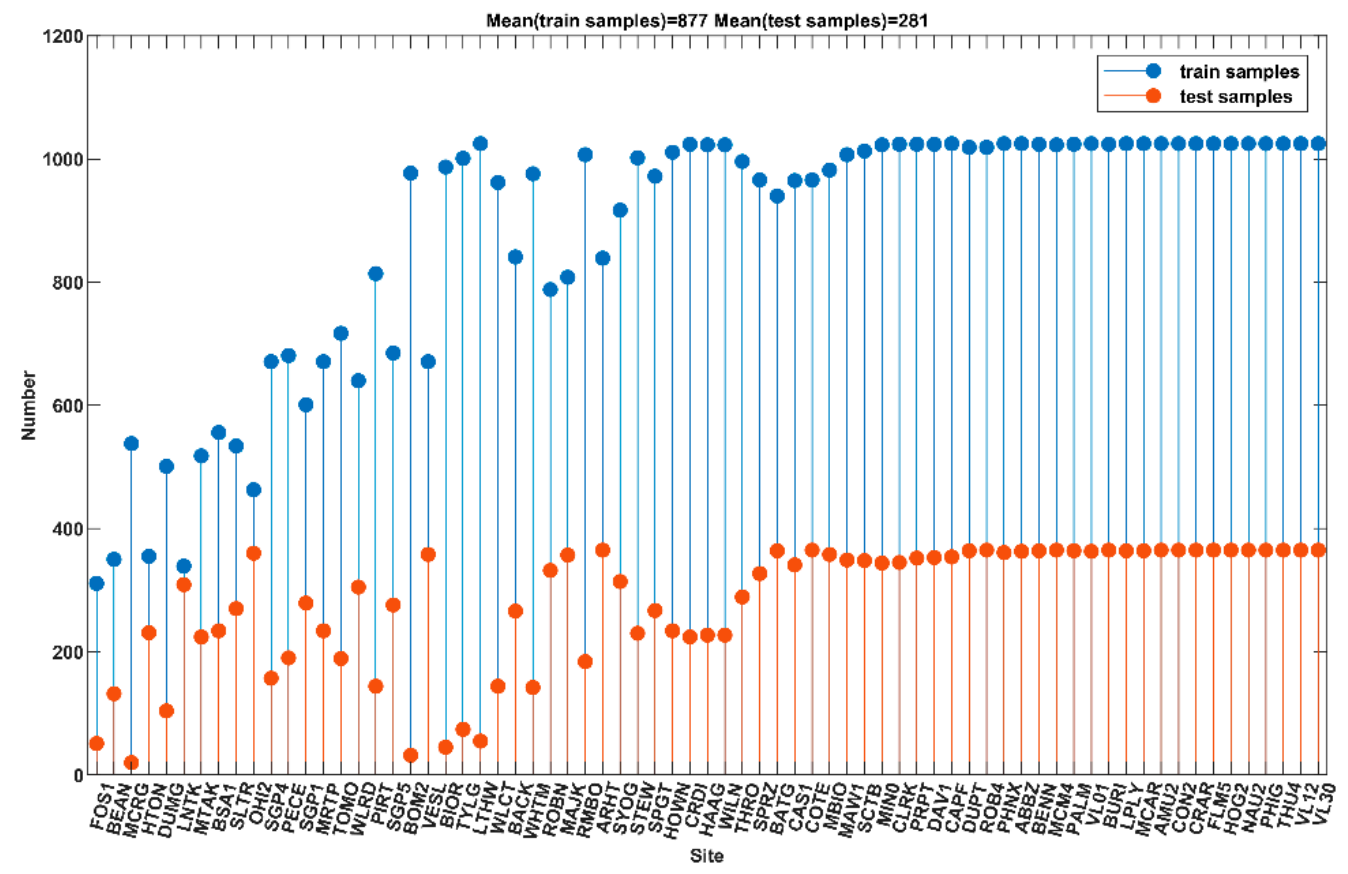

Figure 9. Statistical result of train samples and test samples of LSTM model.

The daily and yearly RMSE were considered as indexes for evaluating accuracy since the forecasting ZTD was obtained day by day, and the total forecast period was one year. Here, the daily and yearly RMSE of GPT3_ZTD, LSTM_ZTD and LSTM_RBF_ZTD were calculated against the reference of GNSS_ZTD at test stations in the forecast period. RMSE was described with the following example of LSTM_RBF_ZTD, while the calculation method for GPT3_ZTD and LSTM_ZTD are similar.

$$
\mathrm{RMSE}=\sqrt{\frac{\sum_{i=1}^{n}\left(\mathrm{LSTM} \_\mathrm{RBF} \_Z \mathrm{ZD}_{i}-\mathrm{GNSS}_{2} \mathrm{ZTD}_{i}\right)^{2}}{n}}
$$

where $n$ represents the number of sampling points in the forecast period, which had a value of 288 for daily RMSE, and a value of 288 multiplied by the number of test samples for yearly RMSE. The yearly RMSE of GPT3_ZTD and that of LSTM_RBF_ZTD were compared 
to determine the improvement, quantifying the outperformance of the proposed model over the GPT3 model.

$$
\text { improvement }=-\frac{\text { yearly } \mathrm{RMSE} \text { LSTM_RBF_ZTD }- \text { yearly } \mathrm{RMSE} \mathrm{GPT}_{\mathrm{G} \_\mathrm{ZTD}}}{\text { yearly } \mathrm{RMSE} \text { GPT3_ZTD }} \times 100 \%
$$

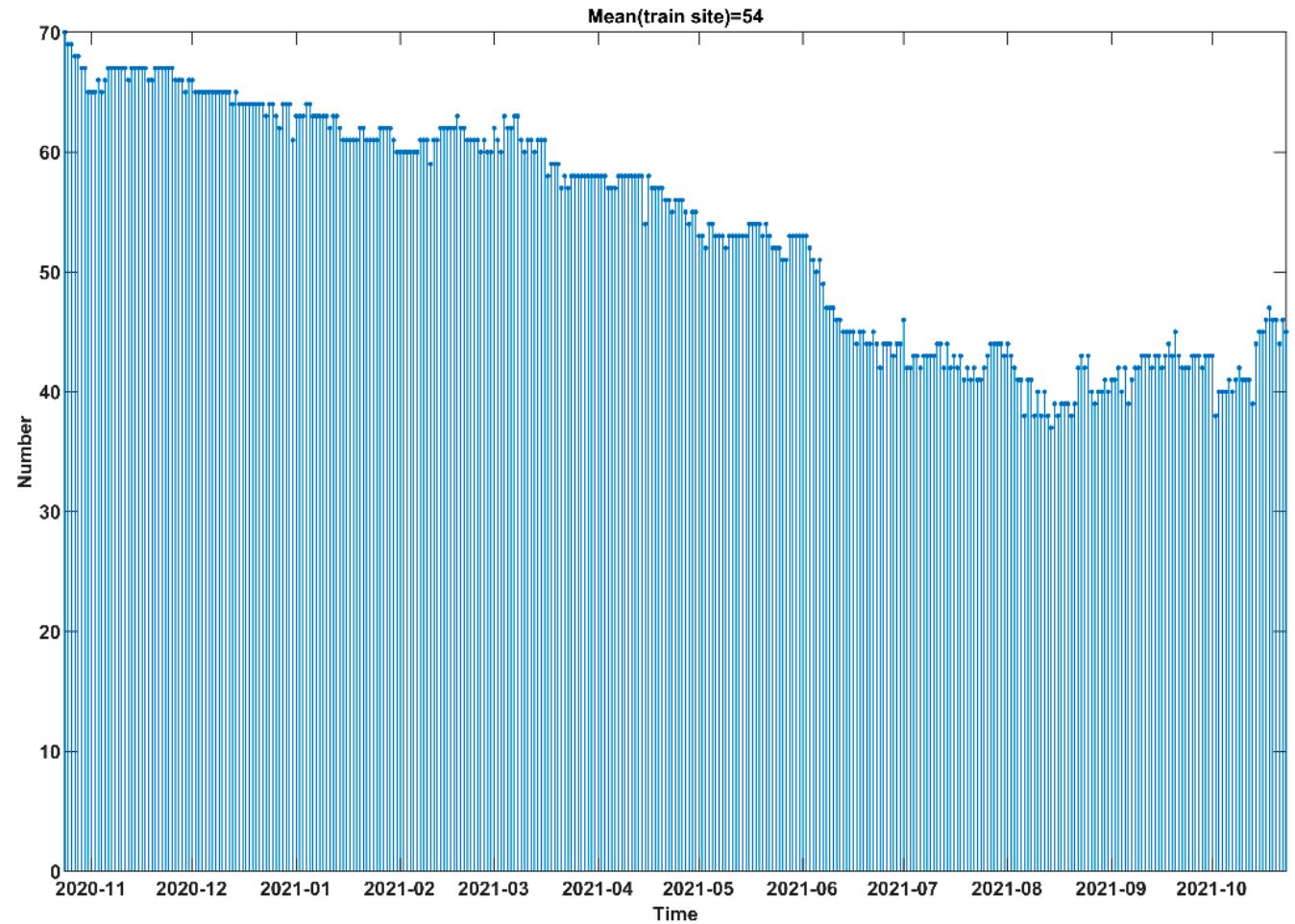

Figure 10. Statistical result of training stations of the RBF model.

\section{Results}

\subsection{Accuracy of the LSTM_ZTD}

For assessing the accuracy of the proposed model, the forecasting results of the LSTM model from 24 October 2020 to 23 October 2021 at PRPT, THU4, MCM4, AMU2 and DAV1 station were used. As shown in the left of Figure 11, the comparison indicates that the LSTM_ZTD series of five stations were in better agreement with GNSS_ZTD, with yearly RMSE values of $17.3 \mathrm{~mm}, 12.4 \mathrm{~mm}, 8.9 \mathrm{~mm}, 6.4 \mathrm{~mm}$ and $11.3 \mathrm{~mm}$, respectively. The range of bias series in the right of Figure 11 was concentrated; the mean bias values were $-3.4 \mathrm{~mm}$, $-3.0 \mathrm{~mm}, 0.3 \mathrm{~mm},-1.1 \mathrm{~mm}$ and $2.1 \mathrm{~mm}$ for five stations. However, the intraday variation of LSTM_ZTD was always too smooth to accord with spike-shaped peaks in one-day GNSS_ZTD, mainly because the output layer of the LSTM model caused daylong bias, providing a low ability to capture hourly bias variation. The statistical daily RMSE of LSTM_ZTD from 24 October 2020 to 23 October 2021 (Figure 12 and Table 1) shows that most daily RMSE values were below $10 \mathrm{~mm}$ at MCM4 and AMU2 stations. RMSE values for MCM4 station were less than $5 \mathrm{~mm}$ on 115 days and within 5-10 mm on 166 days. Daily RMSE was over $10 \mathrm{~mm}$ on 84 days, and the mean daily RMSE value for the 365 days was $7.7 \mathrm{~mm}$. RMSE values for AMU2 station were less than $5 \mathrm{~mm}$ on 193 days and within 5-10 mm on 133 days. Daily RMSE was over $10 \mathrm{~mm}$ on only 39 days, and the mean daily RMSE value for the 365 days was $5.4 \mathrm{~mm}$. The daily RMSE of LSTM-ZTD at THU4 and DAV1 stations were slightly greater than those of MCM4 and AMU2 stations, with mean values of $10.4 \mathrm{~mm}$ and $9.5 \mathrm{~mm}$. respectively. Daily RMSE values were less than $5 \mathrm{~mm}$ for 70 days for THU4 station and 73 days for DAV1 station. They ranged from $5-10 \mathrm{~mm}$ on 143 days for THU4 station and 150 days for DAV1 station. There were 152 days for MCM4 station and 130 days for AMU2 station when the daily RMSE values were more than $10 \mathrm{~mm}$. 
By contrast, the overall daily RMSE of PRPT station was the greatest, with a mean value of $14.5 \mathrm{~mm}$, and 222 days had daily RMSE values over $10 \mathrm{~mm}$. Moreover, most of the daily RMSE values in the warm season (November to March) were smaller than that in the cold season (April to October).

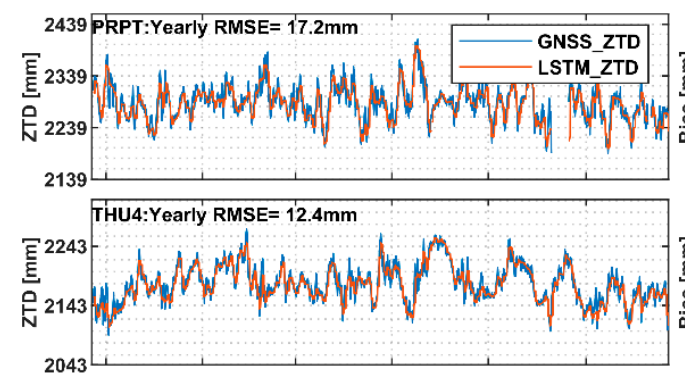

AMU2:Yearly RMSE $=6.4 \mathrm{~mm}$

EMU2:Yearly RMSE $=6.4 \mathrm{~mm}$

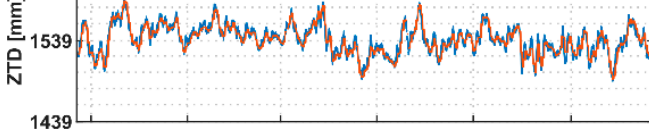

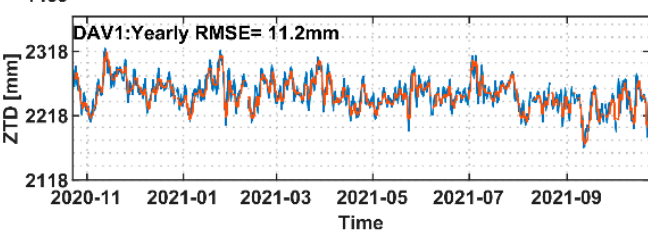

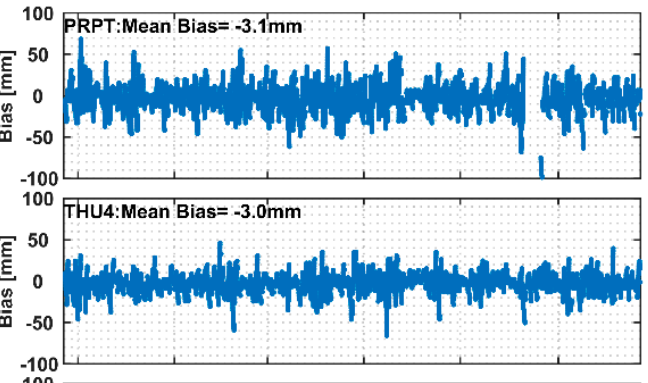

100 MCM4:Mean Bias $=0.3 \mathrm{~mm}$

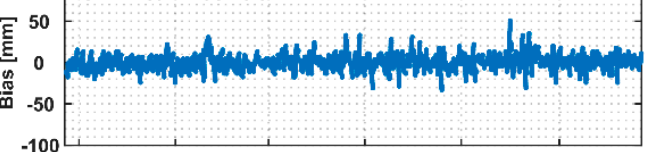

100 AMU2:Mean' Bias $=-1.2 \mathrm{~mm}$

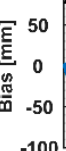

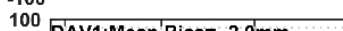

Mean'

晸 50

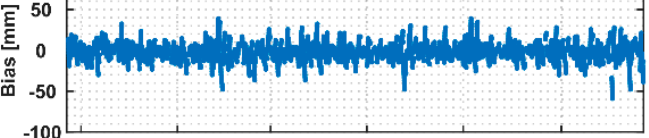

Figure 11. Comparison between LSTM_ZTD and GNSS_ZTD from 24 October 2020 to 23 October 2021 at PRPT, THU4, MCM4, AMU2 and DAV1 station.
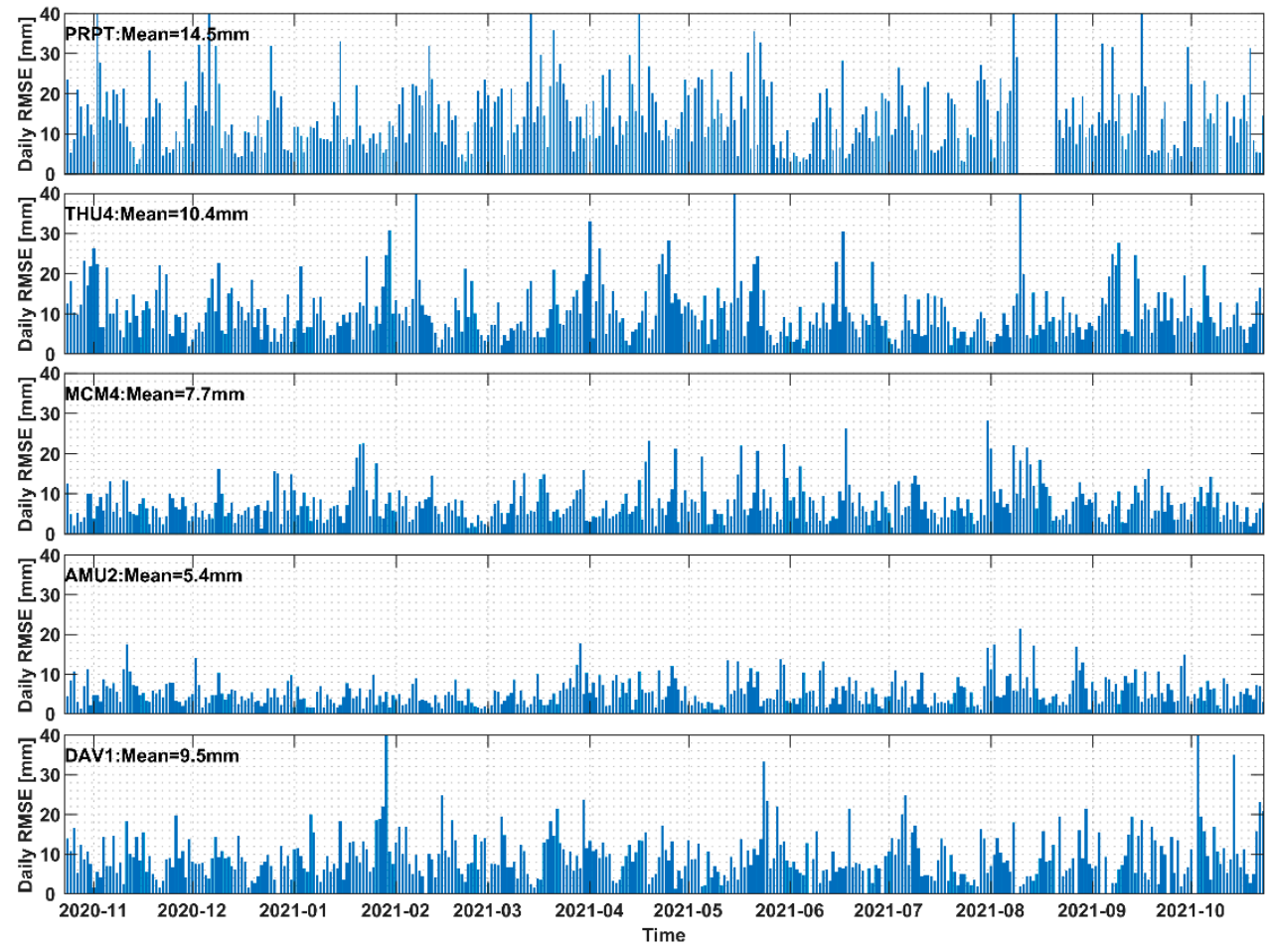

Figure 12. Daily RMSE of LSTM_ZTD from 24 October 2020 to 23 October 2021 at PRPT, THU4, MCM4, AMU2 and DAV1 station. 
Table 1. Daily RMSE piece-wise statistic result of LSTM_ZTD from 24 October 2020 to 23 October 2021 at PRPT, THU4, MCM4, AMU2 and DAV1 station (units: day).

\begin{tabular}{cccc}
\hline Daily RMSE & $\mathbf{0 - 5} \mathbf{~ m m}$ & $\mathbf{5 - 1 0} \mathbf{~ m m}$ & $\mathbf{1 0} \mathbf{~ m m}$ \\
\hline PRPT & 26 & 104 & 222 \\
THU4 & 70 & 143 & 152 \\
MCM4 & 115 & 166 & 84 \\
AMU2 & 193 & 133 & 39 \\
DAV1 & 73 & 150 & 130 \\
mean & 95.4 & 139.2 & 125.4 \\
\hline
\end{tabular}

Figure 13 and Table 2 display the yearly RMSE and daily RMSE of LSTM_ZTD for the forecast period at the 65 stations. The histogram and the box plot in Figure 13 display yearly RMSE and daily RMSE, respectively, and the statistical result of piece-wise yearly RMSE and percentage of daily RMSE are listed in Table 2. For yearly RMSE, values were concentrated in $20 \mathrm{~mm}$ for almost all of the stations. A total of 40 stations had values less than $10 \mathrm{~mm}, 14$ stations had values ranging from 10 to $15 \mathrm{~mm}$, and 9 stations had values ranging from 15 to $20 \mathrm{~mm}$. Only two stations had yearly RMSE greater than $20 \mathrm{~mm}$. The minimum value of $6.4 \mathrm{~mm}$ occurred at the AMU2 station, the maximum was $32.8 \mathrm{~mm}$ at the PHNX station, and the mean value for the 65 stations was $10.9 \mathrm{~mm}$. For the daily RMSE, we took the result of a station as an example to illustrate the symbol in the box plot of Figure 13. Here, the red line is the median of the daily RMSE at a station, and the blue upper box line and lower box line represent, respectively, the upper quartile Q1 and the lower quartile Q3, with $50 \%$ of daily RMSE between Q1 and Q3. The black lines extending above and below the box indicate the maximum and minimum daily RMSE within the nonabnormal range $(\mathrm{Q} 1+1.5 \times[\mathrm{Q} 1-\mathrm{Q} 3] \sim \mathrm{Q} 3-1.5 \times[\mathrm{Q} 1-\mathrm{Q} 3])$. When the value exceeded the range, it was identified as an outlier and is represented in the figure by a red cross. Fewer outliers did not affect the overall daily RMSE and were ignored in the analysis. Moreover, the classification of daily RMSE in Table 2 is arranged based on the position of the red line and the blue upper box line in Figure 13. Below-median (red line) daily RMSE accounted for $50 \%$ of the total, and daily RMSE of less than Q1 (blue upper box line) was $75 \%$, which reflects the distribution of the main daily RMSE. For example, a station was classified as " $50 \%<10 \mathrm{~mm}$ " when its red line was under $10 \mathrm{~mm}$, meaning that at least $50 \%$ of daily RMSE values were less than $10 \mathrm{~mm}$. All statistical results in the figure and table show that the overall daily RMSE values were small and concentrated for most stations, corresponding to yearly RMSE. There were 50 stations with at least $50 \%$ daily RMSE less than $10 \mathrm{~mm}$, and 35 stations with more than $75 \%$ proportion. When the range was extended from $10 \mathrm{~mm}$ to $20 \mathrm{~mm}$, the number of stations with a proportion of daily RMSE of more than $50 \%$ increased to 63 , and the number with a proportion of more than $75 \%$ increased to 63 .

In conclusion, LSTM_ZTD had high consistency with GNSS_ZTD in the forecast period, and millimeter-level forecasting accuracy could be achieved at some GNSS stations. Diverse climates led to a large difference in ZTD variation at different stations, as well as in different seasons. Troposphere delay varied in certain situations, while the LSTM model had a limited learning capacity, resulting in a higher yearly RMSE. LSTM_ZTD could meet the needs of forecasting ZTD for a single station. However, to forecast ZTD more effectively than GPT3_ZTD in space, it was necessary to model and modify GPT3_ZTD in spatial domain based on the LSTM_ZTD of multiple stations. 

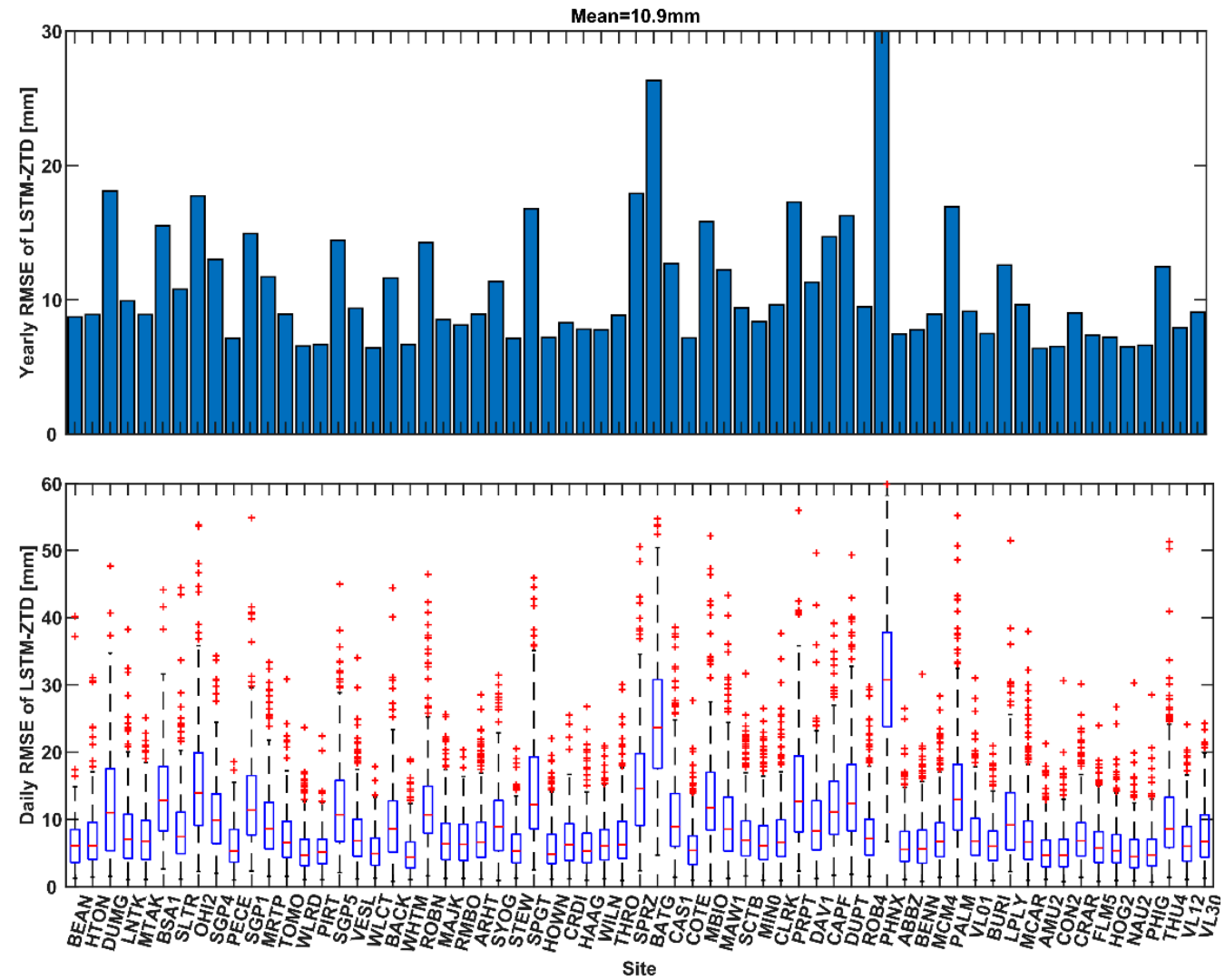

Figure 13. Yearly RMSE and daily RMSE of LSTM_ZTD in the forecast period at 65 stations.

Table 2. Statistical result of piece-wise yearly RMSE and percentage of daily RMSE for 65 stations.

\begin{tabular}{ccc}
\hline & RMSE & Number of sites \\
\hline \multirow{3}{*}{ Yearly RMSE } & $5-10 \mathrm{~mm}$ & 40 \\
& $10-15 \mathrm{~mm}$ & 14 \\
& $15-20 \mathrm{~mm}$ & 9 \\
& $>20 \mathrm{~mm}$ & 2 \\
\hline \multirow{2}{*}{ Daily RMSE } & $50 \%<10 \mathrm{~mm}$ & 50 \\
& $75 \%<10 \mathrm{~mm}$ & 35 \\
& $50 \%<20 \mathrm{~mm}$ & 63 \\
& $75 \%<20 \mathrm{~mm}$ & 63 \\
\hline
\end{tabular}

\subsection{Comparisons between the LSTM_RBF_ZTD and the GPT3_ZTD}

We compared the daily RMSE of LSTM_RBF_ZTD and of GPT3_ZTD at 65 stations with better data coverage in the forecast period, as displayed in Figure 14 and Table 3. The daily RMSE of the LSTM_RBF_ZTD are given in the top box plot of Figure 14, and the bottom box plot shows the daily RMSE of GPT3_ZTD. It is evident that the daily RMSE of LSTM_RBF_ZTD was more concentrated and smaller than GPT3_ZTD. For the daily RMSE of LSTM_RBF_ZTD, the blue boxes were concentrated below $20 \mathrm{~mm}$ for almost all the stations. The maximum and median values were relatively small, with most of the black lines within 10-50 $\mathrm{mm}$ and the red lines under $20 \mathrm{~mm}$. From the quantified statistic in Table 3, there were 31 stations with over $50 \%$ daily RMSE less than $10 \mathrm{~mm}$, and 8 stations with a percentage of $75 \%$ less than $10 \mathrm{~mm}$. Similarly, at least $50 \%$ of the daily RMSE are below $20 \mathrm{~mm}$ for 62 stations, of which there are 47 stations with $75 \%$ of values below $20 \mathrm{~mm}$. For the daily RMSE of GPT3_ZTD, almost all the blue boxes are greater ranging from $10 \mathrm{~mm}$ to $40 \mathrm{~mm}$, with the maximum and median values of more than $40 \mathrm{~mm}$ and $10 \mathrm{~mm}$, respectively. There is no station where the percentage of daily RMSE less than 
$10 \mathrm{~mm}$ can reach $50 \%$ or $75 \%$. Over $50 \%$ of daily RMSE are less than $20 \mathrm{~mm}$ for 39 stations but there are 2 stations where the percentage exceeds $75 \%$.

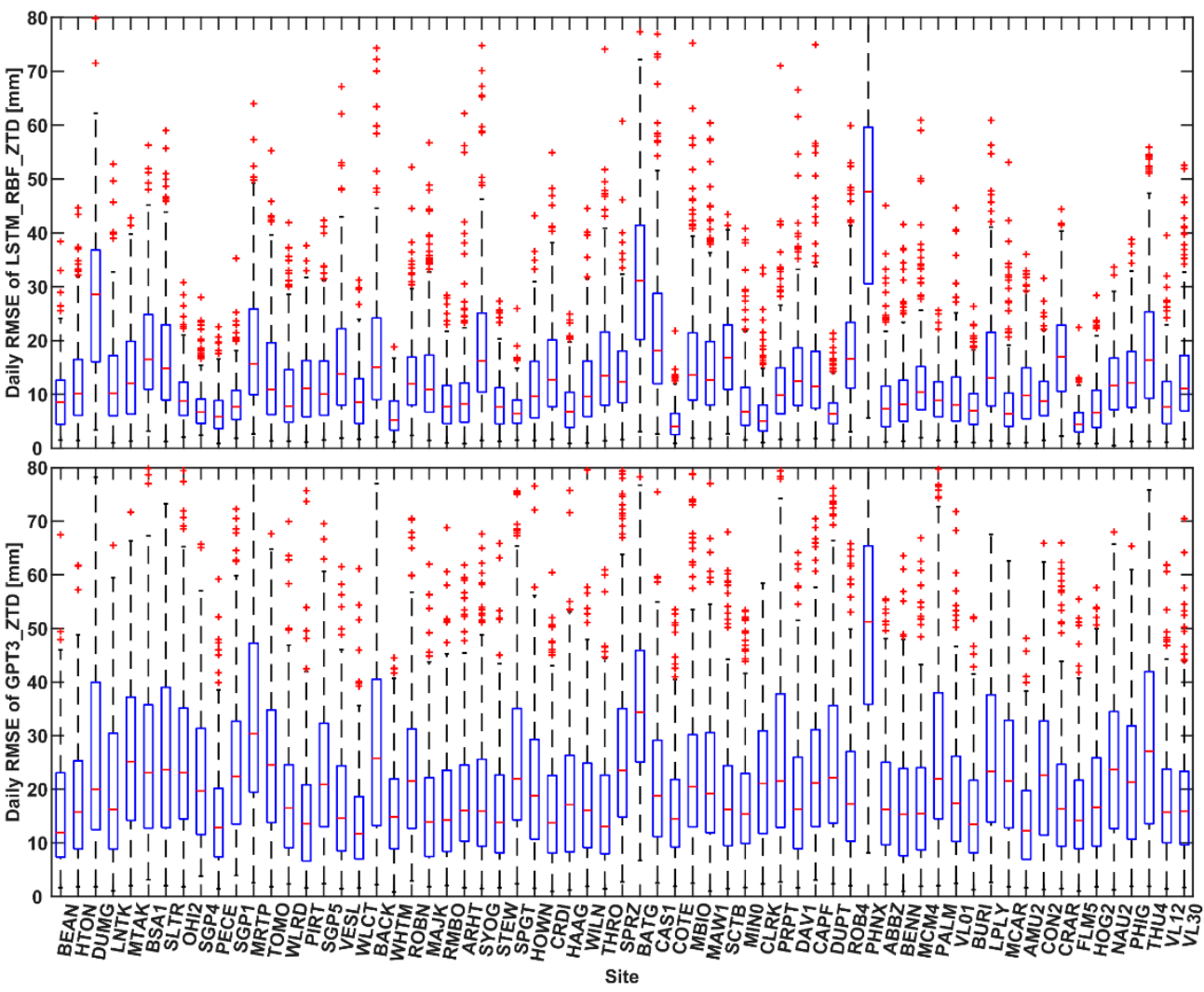

Figure 14. Comparisons between the daily RMSE of LSTM_RBF_ZTD and GPT3_ZTD in forecast period at 65 stations.

Table 3. Statistical percentage of daily RMSE of LSTM_RBF_ZTD and GPT3_ZTD at 65 stations (units: site number).

\begin{tabular}{ccc}
\hline Daily RMSE & LSTM_RBF_ZTD & GPT3_ZTD \\
\hline $50 \%<10 \mathrm{~mm}$ & 31 & 0 \\
$75 \%<10 \mathrm{~mm}$ & 8 & 0 \\
$50 \%<20 \mathrm{~mm}$ & 62 & 39 \\
$75 \%<20 \mathrm{~mm}$ & 47 & 2 \\
\hline
\end{tabular}

Figure 15 and Table 4 illustrate the yearly RMSE of LSTM_RBF_ZTD and GPT3_ZTD at 65 stations. The statistical result for the LSTM_RBF_ZTD shows that the minimum and maximum of yearly RMSE were $5.1 \mathrm{~mm}$ and $50.1 \mathrm{~mm}$, respectively, with an average value of $15.7 \mathrm{~mm}$. There were 52 stations with yearly RMSE smaller than $20 \mathrm{~mm}$, mostly occurring in West Antarctica. There were 12 stations with yearly RMSE smaller than $10 \mathrm{~mm}$, marked in dark blue in the figure. The yearly RMSE ranged from $20 \mathrm{~mm}$ to $30 \mathrm{~mm}$ for 10 stations, mainly located in coastal areas. Only three stations, located in the coastal area of East Antarctica and its islands and shown in yellow or red points in the figure, have yearly RMSE greater than $30 \mathrm{~mm}$. For the yearly RMSE of GPT3_ZTD, the minimum, maximum and mean values were $16.9 \mathrm{~mm}, 54.8 \mathrm{~mm}$ and $25.9 \mathrm{~mm}$, respectively. There were 8 stations with the yearly RMSE ranging from $10 \mathrm{~mm}$ to $20 \mathrm{~mm}$, and most of them were located in the inland of West Antarctica. The majority of the yearly RMSE in the coastal areas and the Antarctic Peninsula was higher than $20 \mathrm{~mm}$, with yearly RMSE between 20 and $30 \mathrm{~mm}$ at 41 stations and more than $30 \mathrm{~mm}$ for 16 stations. 

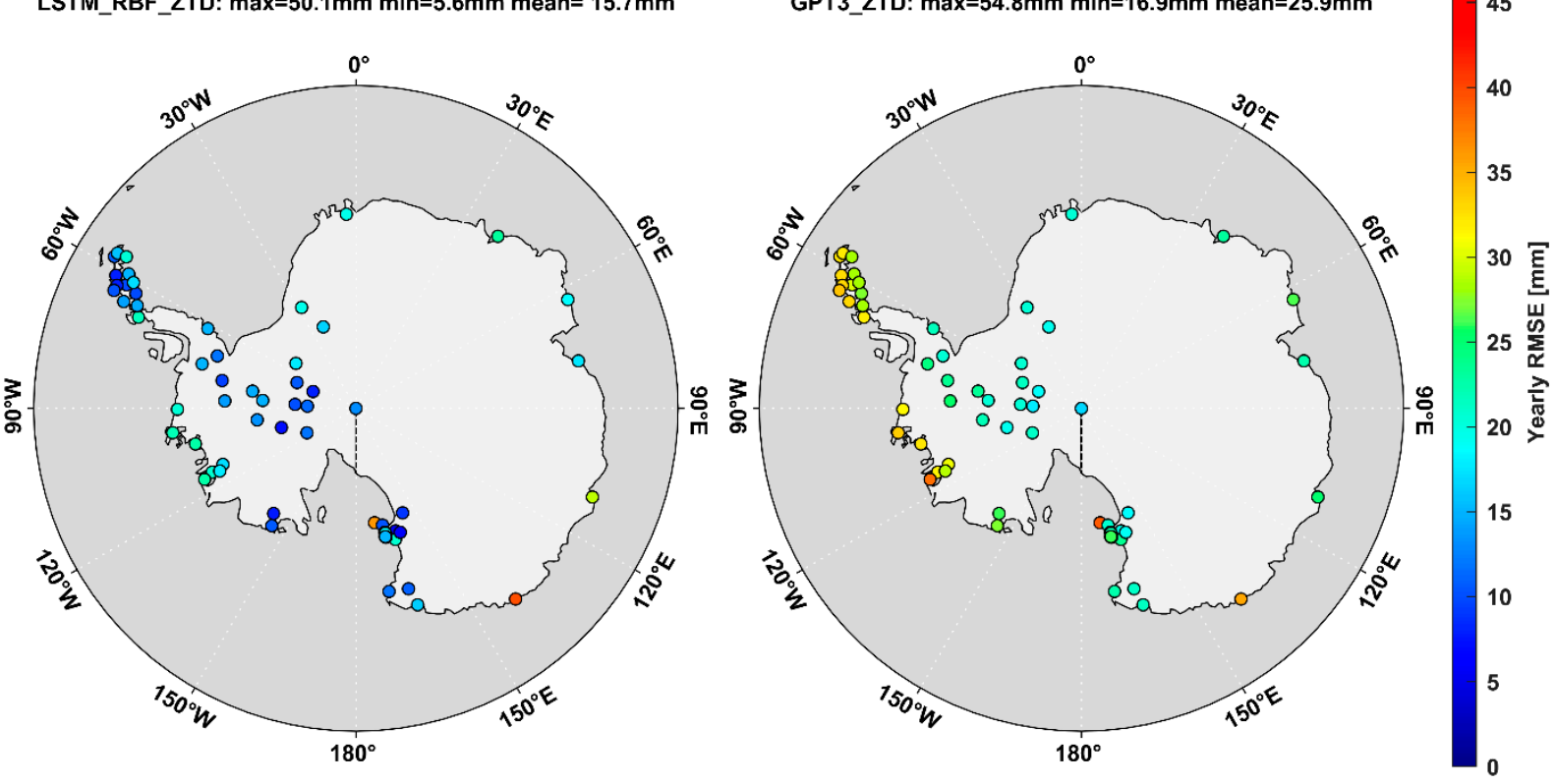

Figure 15. Comparisons between the yearly RMSE of LSTM_RBF_ZTD and GPT3_ZTD in the forecast period at 65 stations.

Table 4. Statistical piece-wise yearly RMSE of LSTM_RBF_ZTD and GPT3_ZTD at 65 stations (units: site number).

\begin{tabular}{ccc}
\hline Yearly RMSE & LSTM_RBF_ZTD & GPT3_ZTD \\
\hline $0-10 \mathrm{~mm}$ & 12 & 0 \\
$10-20 \mathrm{~mm}$ & 40 & 8 \\
$20-30 \mathrm{~mm}$ & 10 & 41 \\
$>30 \mathrm{~mm}$ & 3 & 16 \\
\hline
\end{tabular}

In summary, all statistical results of daily RMSE and yearly RMSE illustrate that the overall accuracy of LSTM_RBF_ZTD is better than that of GPT3_ZTD, with a decrease of the mean yearly RMSE of 65 stations from $25.9 \mathrm{~mm}$ to $15.7 \mathrm{~mm}$. The deviation between GPT3_ZTD and GNSS_ZTD is effectively reduced using the LSTM model and RBF model in Antarctica.

\section{Discussion}

The results in Figure 13 show that the yearly RMSE of GPT3_ZTD is influenced by geographical location. In Antarctica, the inland areas are dominated by plateaus and covered by ice all year round. Severe cold climate and dry air results in scarce water vapor in the troposphere, contributing to small and slight changes of ZTD. The coastal areas are the regions with the greatest synoptic variability in Antarctica, and are affected by the polar low pressure and the strong cold air from the inland areas. The abundant water vapor and strong molecular motion in the troposphere over coastal areas cause larger ZTD values and a higher variability of the ZTD. This is evidenced in the five stations located in these areas, as shown in Figure 3. However, since the GPT3 model was developed using global meteorological reanalysis data, the ability to estimate parameters is fixed. Therefore, the accuracy of GPT3_ZTD is higher in areas where the climate changes only slightly, and accuracy is lower in some regions with diverse and complicated climates.

The comparison in Figure 15 shows that the yearly RMSE of LSTM_RBF_ZTD is limited not only by GPT3_ZTD but also by the distribution of the training stations. The overall 
LSTM_RBF_ZTD is more accurate than GPT3_ZTD, and the distribution characteristics of yearly RMSE are similar in most areas. Unlike the yearly RMSE distribution of GPT3_ZTD, the yearly RMSE of LSTM_RBF_ZTD in the Antarctic Peninsula is close to that obtained for the inland stations. This difference indicates that the LSTM_RBF_ZTD has more advantages over GPT3_ZTD in the Antarctic Peninsula, which is also illustrated by the numerical improvement that can be seen in Figure 16. The statistical result in Figure 16 shows that the LSTM_RBF_ZTD outperforms the GPT3_ZTD for 62 stations, and only three stations' results show a decrease in the accuracy of LSTM_RBF_ZTD, as denoted by dots with red edges. The minimum and maximum improvements are $-15.5 \%$ and $76.3 \%$, respectively, with an average value of $39.6 \%$. The dark blue dots, indicating low improvement, are mostly scattered in the coastal areas of the East Antarctica, and the higher improvement, indicated by the red and yellow points, predominately occur in the Antarctic Peninsula, the in inland region of West Antarctica and on Ross Island. This is because the accuracy of the RBF model depends on the inputting training samples. If the correlation between training samples and test samples is strong, the RBF model can fully learn the characteristics of the parameters and accurately estimate the output variables of test samples, and vice versa. That is, the RBF model performs better for test stations located in regions with dense training stations, such as the Antarctic Peninsula and Ross Island. For test stations in an area with sparsely distributed stations, such as East Antarctica, the parameters of the training stations have a poor correlation with that of the test stations. The difference between the GPT3_ZTD and the LSTM_ZTD is estimated with insufficient accuracy by the RBF model, resulting in lower improvement of LSTM_RBF_ZTD over GPT3_ZTD, as well as decreased accuracy for some stations.

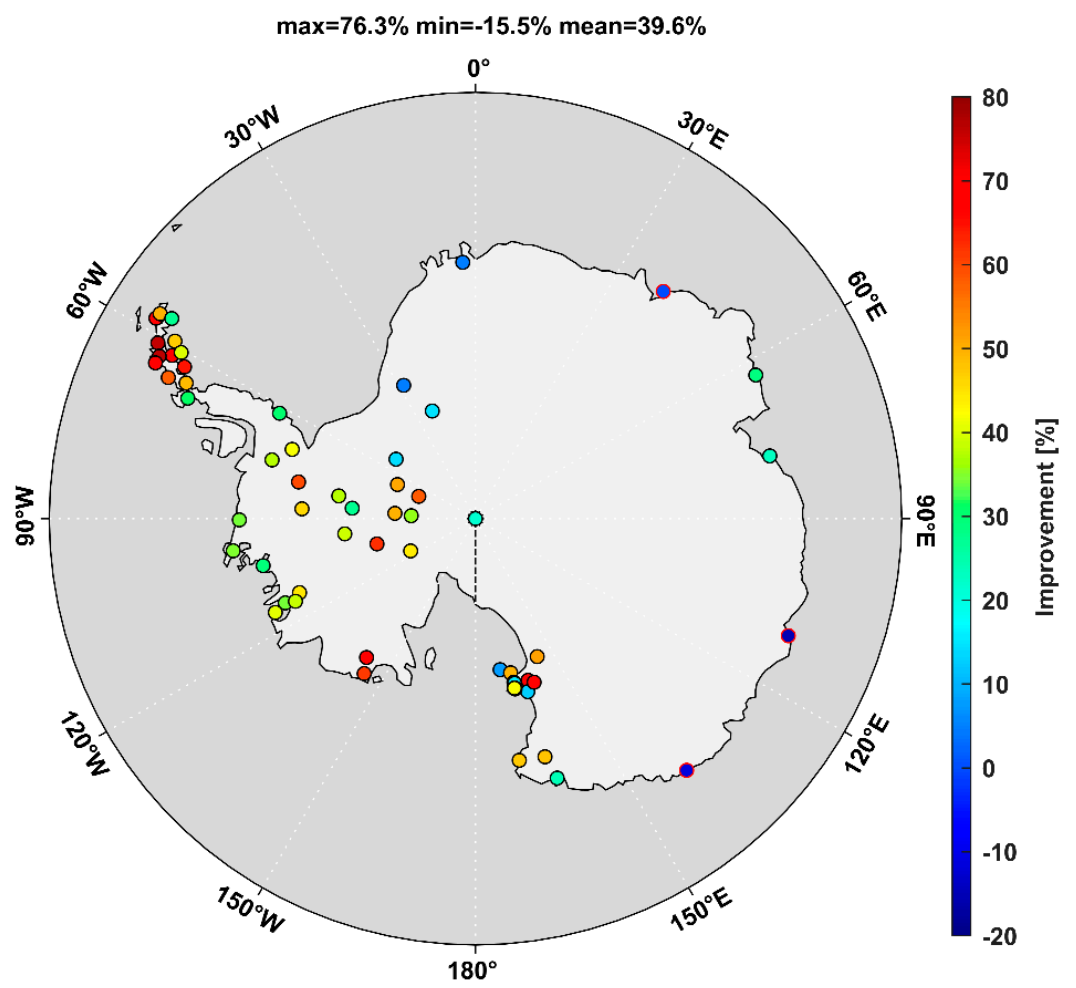

Figure 16. Improvement of LSTM_RBF_ZTD over GPT3_ZTD in forecast period at 65 stations.

\section{Conclusions}

In order to improve the poor performance of the GPT3 model in estimating ZTD in Antarctica, we introduced LSTM and RBF neural networks to enhance GPT3_ZTD in time and space, respectively, and develop a high-precision ZTD forecasting model in Antarctica. The GNSS_ZTD of 71 GNSS stations in Antarctica, with an observation period from 1 January 2018 to 23 October 2021, were selected from the NGL Analysis Center as the 
reference data. The forecast results from 24 October 2020 to 23 October 2021 at 65 stations (with test samples more than 100 days in forecast periods) are shown.

The series of differences between GPT3_ZTD and GNSS_ZTD at five representative stations (PRPT, THU4, MCM4, AMU2 and DAV1) have strong autocorrelation that decreases with the periodic lag of epoch 288. The forecasting LSTM_ZTD is highly consistent with GNSS_ZTD. For the LSTM_ZTD of the 65 stations, there are 40 stations with the subcentimeter yearly RMSE and the average yearly RMSE for the 65 stations is $10.9 \mathrm{~mm}$. In general, the LSTM model performs well in forecasting the variation trend of the day-to-day bias between GNSS_ZTD and GPT3_ZTD, and LSTM_ZTD values are close to GNSS_ZTD and quite stable.

The LSTM_RBF_ZTD is more accurate than the GPT3_ZTD at 65 test stations. The daily RMSE of LSTM_RBF_ZTD has a lower variation and is smaller than that of GPT3_ZTD; the mean yearly RMSE for the 65 stations decreased from $25.9 \mathrm{~mm}$ to $15.7 \mathrm{~mm}$. GPT3_ZTD is significantly improved at 62 stations. LSTM_RBF_ZTD delivered worse results than GPT3_ZTD at only three stations. The improvement of LSTM_RBF_ZTD over GPT3_ZTD ranges from $-15.5 \%$ to $76.3 \%$, with the average value for the full set of 65 stations reaching $39.6 \%$.

In addition, the GPT3 model has limited ability to capture complicated synoptic variability, leading to a worse performance in estimating ZTD, which is more significant in coastal areas than in inland. The accuracy of LSTM_RBF_ZTD is restricted by the external constraints of GPT3_ZTD and the spatial distribution of the stations. LSTM_RBF_ZTD performs better in West Antarctica where the stations are densely distributed, especially in the Antarctic Peninsula and Ross Island. In general, the model proposed in this work has significantly better performance in comparison to the GPT3 model for estimating ZTD in Antarctica.

Author Contributions: Conceptualization, T.X.; methodology, S.L.; software, S.L.; validation, T.X., Y.X. and N.J.; formal analysis, S.L.; investigation, S.L., Y.X. and N.J.; resources, T.X.; data curation, S.L.; writing —original draft preparation, S.L.; writing-review and editing, S.L., T.X., Y.X., N.J. and L.B.; visualization, S.L.; supervision, T.X.; project administration, T.X.; funding acquisition, T.X. and Y.X. All authors have read and agreed to the published version of the manuscript.

Funding: This study is financially supported by the National Natural Science Foundation of China (41874032), Natural Science Foundation of Shandong Province, China (ZR2020QD046 and ZR2020MD045) and Young Scholars Program of Shandong University, Weihai (YSPSDUWH 20820211007).

Institutional Review Board Statement: Not applicable.

Informed Consent Statement: Informed consent was obtained from all subjects involved in the study.

Data Availability Statement: Not applicable.

Acknowledgments: The authors would like to extend their sincere gratitude to NGL providing the relevant data.

Conflicts of Interest: The authors declare no conflict of interest.

\section{References}

1. Suparta, W.; Abdul Rashid, Z.A.; Mohd Ali, M.A.; Yatim, B.; Fraser, G.J. Observations of Antarctic precipitable water vapor and its response to the solar activity based on GPS sensing. J. Atmos. Sol. Terr. Phys. 2008, 70, 1419-1447. [CrossRef]

2. Vázquez, B.G.E.; Grejner-Brzezinska, D.A. GPS-PWV estimation and validation with radiosonde data and numerical weather prediction model in Antarctica. GPS Solut. 2012, 17, 29-39. [CrossRef]

3. Li, W.; Yuan, Y.; Ou, J.; Li, H.; Li, Z. A new global zenith tropospheric delay model IGGtrop for GNSS applications. Chin. Sci. Bull. 2012, 57, 2132-2139. [CrossRef]

4. Li, W.; Yuan, Y.; Ou, J.; He, Y. IGGtrop_SH and IGGtrop_rH: Two Improved Empirical Tropospheric Delay Models Based on Vertical Reduction Functions. IEEE Trans. Geosci. Remote Sens. 2018, 56, 5276-5288. [CrossRef]

5. Li, W.; Yuan, Y.; Ou, J.; Chai, Y.; Li, Z.; Liou, Y.-A.; Wang, N. New versions of the BDS/GNSS zenith tropospheric delay model IGGtrop. J. Geod. 2014, 89, 73-80. [CrossRef] 
6. Yao, Y.; Xu, C.; Zhang, B.; Cao, N. A global empirical model for mapping zenith wet delays onto precipitable water vapor using GGOS Atmosphere data. Sci. China Earth Sci. 2015, 58, 1361-1369. [CrossRef]

7. Yao, Y.; Hu, Y.; Yu, C.; Zhang, B.; Guo, J. An improved global zenith tropospheric delay model GZTD2 considering diurnal variations. Nonlinear Processes Geophys. 2016, 23, 127-136. [CrossRef]

8. Sun, L.; Chen, P.; Wei, E.; Li, Q. Global model of zenith tropospheric delay proposed based on EOF analysis. Adv. Space Res. 2017, 60, 187-198. [CrossRef]

9. Wang, S.; Xu, T.; Nie, W.; Jiang, C.; Yang, Y.; Fang, Z.; Li, M.; Zhang, Z. Evaluation of Precipitable Water Vapor from Five Reanalysis Products with Ground-Based GNSS Observations. Remote Sens. 2020, 12, 1817. [CrossRef]

10. Li, S.; Xu, T.; Jiang, N.; Yang, H.; Wang, S.; Zhang, Z. Regional Zenith Tropospheric Delay Modeling Based on Least Squares Support Vector Machine Using GNSS and ERA5 Data. Remote Sens. 2021, 13, 1004. [CrossRef]

11. Huang, L.; Mo, Z.; Liu, L.; Zeng, Z.; Chen, J.; Xiong, S.; He, H. Evaluation of Hourly PWV Products Derived From ERA5 and MERRA-2 Over the Tibetan Plateau Using Ground-Based GNSS Observations by Two Enhanced Models. Earth Space Sci. 2021, 8, e2020EA001516. [CrossRef]

12. Jiang, C.; Xu, T.; Wang, S.; Nie, W.; Sun, Z. Evaluation of Zenith Tropospheric Delay Derived from ERA5 Data over China Using GNSS Observations. Remote Sens. 2020, 12, 663. [CrossRef]

13. Huang, L.; Guo, L.; Liu, L.; Chen, H.; Chen, J.; Xie, S. Evaluation of the ZWD/ZTD Values Derived from MERRA-2 Global Reanalysis Products Using GNSS Observations and Radiosonde Data. Sensors 2020, 20, 6440. [CrossRef] [PubMed]

14. Huang, L.; Zhu, G.; Liu, L.; Chen, H.; Jiang, W. A global grid model for the correction of the vertical zenith total delay based on a sliding window algorithm. GPS Solut. 2021, 25, 98. [CrossRef]

15. Leandro, R.F.; Langley, R.B.; Santos, M.C. UNB3m_pack: A neutral atmosphere delay package for radiometric space techniques GPS Solut. 2007, 12, 65-70. [CrossRef]

16. Penna, N.; Dodson, A.; Chen, W. Assessment of EGNOS Tropospheric Correction Model. J. Navig. 2001, 54, 37-55. [CrossRef]

17. Schuh, J.B.R.H.H. Short Note: A global model of pressure and temperature for geodetic applications. J. Geod. 2007, 81, 679-683. [CrossRef]

18. Böhm, J.; Möller, G.; Schindelegger, M.; Pain, G.; Weber, R. Development of an improved empirical model for slant delays in the troposphere (GPT2w). GPS Solut. 2014, 19, 433-441. [CrossRef]

19. Lagler, K.; Schindelegger, M.; Bohm, J.; Krasna, H.; Nilsson, T. GPT2: Empirical slant delay model for radio space geodetic techniques. Geophys. Res. Lett. 2013, 40, 1069-1073. [CrossRef]

20. Landskron, D.; Bohm, J. VMF3/GPT3: Refined discrete and empirical troposphere mapping functions. J. Geod. 2018, 92, 349-360. [CrossRef] [PubMed]

21. Yibin, Y.; Na, C.; Chaoqian, X.; Junjian, Y. Accuracy Assessment and Analysis for GPT2. Acta Geod. Cartogr. Sin. 2015, 44, 726-733. [CrossRef]

22. Jian, K.; Yibin, Y.; Lulu, S.; Zemin, W. The Accuracy Analysis of GPT2w at the Antarctic Area. Acta Geod. Cartogr. Sin. 2018, 47, 1316-1325. [CrossRef]

23. Yang, F.; Guo, J.; Meng, X.; Li, J.; Zou, J.; Xu, Y. Establishment and assessment of a zenith wet delay (ZWD) augmentation model GPS Solut. 2021, 25, 148. [CrossRef]

24. Zhang, Q.; Li, F.; Zhang, S.; Li, W. Modeling and Forecasting the GPS Zenith Troposphere Delay in West Antarctica Based on Different Blind Source Separation Methods and Deep Learning. Sensors 2020, 20, 2343. [CrossRef]

25. Du, Z.; Zhao, Q.; Yao, W.; Yao, Y. Improved GPT2w (IGPT2w) model for site specific zenith tropospheric delay estimation in China. J. Atmos. Sol.-Terr. Phys. 2020, 198, 105202. [CrossRef]

26. Blewitt, G.; Hammond, W.C.; Kreemer, C. Harnessing the GPS data explosion for interdisciplinary science. Eos 2018, $99,485$. [CrossRef]

27. Ding, J.; Chen, J. Assessment of Empirical Troposphere Model GPT3 Based on NGL's Global Troposphere Products. Sensors 2020, 20, 3631. [CrossRef]

28. Saastamoinen, J. Atmospheric Correction for the Troposphere and Stratosphere in Radio Ranging Satellites. In Use of Aritificial Satellites for Geodesy; Wiley: Hoboken, NJ, USA, 1972; Volume 15.

29. Askne, J.; Nordius, H. Estimation of tropospheric delay for microwaves from surface weather data. Radio Sci. 1987, 22, 379-386. [CrossRef]

30. Hochreiter, S.; Schmidhuber, J. Long short-term memory. Neural. Comput. 1997, 9, 1735-1780. [CrossRef]

31. Broomhead, D.S. Multivar iable Functional Interpolation and Adaptive Networks. Complex Syst. 1988, 2, 321-355. 